\title{
Inhibition of Src kinase activity attenuates amyloid associated microgliosis in a murine model of Alzheimer's disease
}

\author{
Gunjan Dhawan ${ }^{1}$ and Colin K Combs ${ }^{*}$
}

\begin{abstract}
Background: Microglial activation is an important histologic characteristic of the pathology of Alzheimer's disease $(A D)$. One hypothesis is that amyloid beta $(A \beta)$ peptide serves as a specific stimulus for tyrosine kinase-based microglial activation leading to pro-inflammatory changes that contribute to disease. Therefore, inhibiting A $\beta$ stimulation of microglia may prove to be an important therapeutic strategy for AD.

Methods: Primary murine microglia cultures and the murine microglia cell line, BV2, were used for stimulation with fibrillar A $\beta 1-42$. The non-receptor tyrosine kinase inhibitor, dasatinib, was used to treat the cells to determine whether Src family kinase activity was required for the $A \beta$ stimulated signaling response and subsequent increase in TNFa secretion using Western blot analysis and enzyme-linked immunosorbent assay (ELISA), respectively. A histologic longitudinal analysis was performed using an AD transgenic mouse model, APP/PS1, to determine an age at which microglial protein tyrosine kinase levels increased in order to administer dasatinib via mini osmotic pump diffusion. Effects of dasatinib administration on microglial and astroglial activation, protein phosphotyrosine levels, active Src kinase levels, $A \beta$ plaque deposition, and spatial working memory were assessed via immunohistochemistry, Western blot, and T maze analysis.

Results: $A \beta$ fibrils stimulated primary murine microglia via a tyrosine kinase pathway involving Src kinase that was attenuated by dasatinib. Dasatinib administration to APP/PS1 mice decreased protein phosphotyrosine, active Src, reactive microglia, and TNFa levels in the hippocampus and temporal cortex. The drug had no effect on GFAP levels, A $\beta$ plaque load, or the related tyrosine kinase, Lyn. These anti-inflammatory changes correlated with improved performance on the T maze test in dasatinib infused animals compared to control animals.

Conclusions: These data suggest that amyloid dependent microgliosis may be Src kinase dependent in vitro and in vivo. This study defines a role for Src kinase in the microgliosis characteristic of diseased brains and suggests that particular tyrosine kinase inhibition may be a valid anti-inflammatory approach to disease. Dasatinib is an FDAapproved drug for treating chronic myeloid leukemia cancer with a reported ability to cross the blood-brain barrier. Therefore, this suggests a novel use for this drug as well as similar acting molecules.
\end{abstract}

\section{Introduction}

Amyloid beta deposition and microglial activation are two major pathophysiologic hallmarks of the progression of Alzheimer's disease, often suggested to be associated with each other [1-9]. Microglia are the resident phagocytes of the central nervous system. In the AD brain, microglia are found in a highly activated state often in

\footnotetext{
* Correspondence: colin.combs@med.und.edu

${ }^{2}$ School of Medicine and Health Sciences, 504 Hamline St., Room 118, Grand Forks, ND 58203, USA

Full list of author information is available at the end of the article
}

association with senile plaques [10-13]. Activated microglia present a different phenotype as compared to resting microglia, and are responsible for, in particular, pro-inflammatory cytokine secretions [10-18]. A $\beta$ accumulation in $\mathrm{AD}$ has been associated with these increases in pro-inflammatory markers [19-25]. A $\beta$ peptide has the ability to self-aggregate to form oligomers and fibrils. Both forms have been reported to have neurotoxic and gliotic actions in vitro as well as in vivo [24-36]. Because of the close proximity of reactive microglia to deposited fibrils of $A \beta$, it is hypothesized that $A \beta$ acts as a stimulus 
for microglial activation during disease to initiate or propagate the inflammatory changes observed. Therefore, there is a need to identify a therapeutically approachable microglial target for reducing inflammation in the brains of $\mathrm{AD}$ patients. Based upon the fact that recent data demonstrate that prolonged non-steroidal antiinflammatory drug use decreases incidence of $\mathrm{AD}$ when taken by asymptomatic individuals, an anti-inflammatory approach to disease may be an effective prevention strategy [37]. It is imperative to understand the mechanism(s) by which microglia become reactive to better design anti-inflammatory drug strategies.

Although data suggest a causative role of $A \beta$ deposition for microgliosis, the underlying mechanisms involved are not fully resolved [10,18,28,38-41]. It has been demonstrated through a variety of studies that $\mathrm{A} \beta$ is capable of stimulating microglia in vitro and in vivo to increase protein phosphotyrosine levels. This correlates well with the reported increase in microglial phospho-tyrosine immunoreactivity in $\mathrm{AD}$ brains [42]. These data have supported a hypothesis that the increase in phosphotyrosine immunoreactivity is due to either increased tyrosine kinase activity or decreased tyrosine phosphatase activity. It appears that both scenarios may be true. Microglia can use a multi-receptor complex for interacting with $A \beta$ fibrils on the plasma membrane [43]. Upon ligand binding, a specific signaling pathway is activated involving propagation and downstream increased activation of numerous non-receptor tyrosine kinases, including Src, Lyn, FAK and PYK2 [24,28,39,41,44-47]. Based upon inhibition studies, the increased tyrosine kinase enzyme activities upon $A \beta$ binding are absolutely critical for microgliosis to occur $[24,28,39,41,44-47]$. In fact, it appears that not only increased tyrosine kinase activity is required for $A \beta$ stimulation but also decreased tyrosine phosphatase activity $[48,49]$. Our prior work demonstrated that both oligomeric and fibrillar forms of $A \beta$ stimulate increased protein phosphotyrosine levels in vitro and in vivo that correlated with activation of non-receptor tyrosine kinases $[38,50]$. Irrespective of the form of $\mathrm{A} \beta$ involved, one common mechanism of action appears to be involvement of tyrosine kinases leading to increased secretion of proinflammatory cytokines. This study tests whether inhibition of the $A \beta$ fibril-stimulated signaling response, more precisely nonreceptor tyrosine kinase activity, can attenuate microgliosis both in vitro and in vivo. The Src-Abl inhibitor, dasatinib, was used to treat primary murine microglia cultures in vitro. In order to quantify effects of dasatinib in a more physiologically relevant form of disease, the drug was also administered to a transgenic mouse model of AD. This APP/PS1 mouse line expresses a Swedish mutation in APP and a deltaE9 mutation of presenilin 1 (PS1). The mice over-express human $A \beta$ with a correlating high $A \beta$ plaque immunoreactivity and microgliosis $[51,52]$.

In this work, we demonstrated using primary murine microglia cultures that dasatinib was able to attenuate the $\mathrm{A} \beta$-dependent increase in overall protein phospho-tyrosine levels and active levels of Src and Lyn non-receptor tyrosine kinases which correlated with decreased TNF $\alpha$ secretion. In addition to the in vitro analyses, dasatinib was able to reduce active Src but not Lyn levels as well as TNF $\alpha$ and microgliosis in the APP/PS1 mice following 28 days of subcutaneous infusion. Our study indicates that attenuation of specific non-receptor tyrosine kinase activities, in our case using an FDA approved cancer drug, dasatinib, may be therapeutically useful as a novel anti-inflammatory approach to AD.

\section{Methods}

\section{Materials}

Anti-A $\beta$, clones $6 \mathrm{E} 10$ and 4G8 were from Covance (Emeryville, CA, USA). The anti-Lyn antibody, anti-Src, anti- $\alpha$-tubulin antibodies, FITC and Texas Red conjugated secondary antibodies, and horseradish peroxidase conjugated secondary antibodies were purchased from Santa Cruz Biotechnology (Santa Cruz, CA, USA). Mouse TNF- $\alpha$ Elisa kit was obtained from R\&D Systems (Minneapolis, MN, USA). Anti-phosphotyrosine (4G10) antibody was from EMD Millipore (Billerica, MA, USA) and anti-pLyn (Tyr 396) antibody was purchased from Abcam (Cambridge, MA, USA). Anti-Iba1 antibody was from Wako Chemicals USA, Inc (Richmond, VA, USA). Elite Vectastain $\mathrm{ABC}$ avidin and biotin and alkaline phosphatase kits, biotinylated anti-rabbit, anti-mouse, and anti-rat antibodies and the Vector VIP and Vector Blue chromogen kits were from Vector Laboratories Inc. (Burlingame, CA, USA). Anti-CD68 was obtained from Serotec (Raleigh, NC, USA). Anti-PSD95 and anti-pSrc (Tyr416) antibodies were purchased from Cell Signaling Technology (Danvers, MA, USA). Anti-APP antibody was purchased from Invitrogen (Camarillo, CA, USA). Synaptophysin and BIII tubulin antibodies were purchased from Chemicon International, Inc (Temecula, CA, USA). The non-receptor tyrosine kinase inhibitor, dasatinib, was obtained from LC Laboratories (Woburn, MA, USA). The transgenic mouse line, strain 005864 B6. $\mathrm{Cg}-\mathrm{Tg}$ (APPswe,PSEN1dE9)85Dbo/J and wild type mouse line, C57BL/6 were obtained from the Jackson Laboratory (Bar Habor, ME, USA).

\section{Animal use}

All animal use was approved by the University of North Dakota Institutional Animal Care and Use Committee (UND IACUC). Mice were provided food and water ad libitum and housed in a $12 \mathrm{~h}$ light:dark cycle. The 
investigation conforms to the National Research Council of the National Academies Guide for the Care and Use of Laboratory Animals ( $8^{\text {th }}$ edition).

\section{BV2 cell line}

Immortalized murine microglial BV2 cells were obtained from Dr. Gary E. Landreth, Cleveland, OH, USA. The cells were maintained at $3 \times 10^{6}$ cells/dish in $100-\mathrm{mm}$ dishes in DMEM/F12 (Gibco RBL, Rockville, MD, USA) supplemented with $10 \%$ heat-inactivated fetal bovine serum (FBS) (U.S. Biotechnologies Inc., Parkerford, PA, USA), 5\% horse serum (Equitech-Bio, Inc., Kerrville, TX, USA), penicillin G (100 units/ml), streptomycin $(100 \mathrm{mg} / \mathrm{ml})$, and L-glutamine $(2 \mathrm{mM})$ and incubated at $37^{\circ} \mathrm{C}$ in a humidified atmosphere containing $5 \% \mathrm{CO}_{2}$ and $95 \%$ air.

\section{Murine microglia culture}

Microglia were derived, as described previously [53], from the brains of postnatal day 1 to $3 \mathrm{C} 57 \mathrm{BL} / 6 \mathrm{~J}$ mice. Briefly, meninges-free cortices were removed, trypsinized and triturated in microglia media (DMEM/F12 media containing L-Glutamine (Invitrogen, Carlsbad, CA, USA) and $20 \%$ heat inactivated FBS) and placed in T-75 flasks. The media in the flasks was replaced completely after $24 \mathrm{~h}$ and partially after 7 days with fresh media. The cells were ready to harvest and count after 14 days.

\section{Cell stimulation}

A $\beta$ 1-42 fibrils (American Peptide, Sunnyvale, CA, USA) were prepared according to an established protocol [54]. Microglia were stimulated by removing them from growth media into serum-free DMEM/F12 media containing $\mathrm{A} \beta$ fibrils. To assess dasatinib effects, BV2 or microglia were pretreated with the drug for 30 minutes before $A \beta$ stimulations. For Western blot analyses, fiveminute $A \beta$ stimulations were performed and cells were lysed using radioimmunoprecipitation assay buffer (RIPA) (20 mM Tris, pH 7.4, $150 \mathrm{mM} \mathrm{NaCl,} 1 \mathrm{mM}$ Na3VO4 $10 \mathrm{mM}$ NaF, $1 \mathrm{mM}$ EDTA, $1 \mathrm{mM}$ EGTA, $0.2 \mathrm{mM}$ phenylmethylsulfonyl fluoride, $1 \%$ Triton X-100, $0.1 \%$ SDS, and $0.5 \%$ deoxycholate) with protease inhibitors (AEBSF $104 \mathrm{mM}$, Aprotinin $0.08 \mathrm{mM}$, Leupeptin $2.1 \mathrm{mM}$, Bestatin $3.6 \mathrm{mM}$, Pepstatin A $1.5 \mathrm{mM}$, E$64 \mathrm{mM}$ ). Protein concentrations were determined using the Bradford method [55]. For ELISA and toxicity analyses, cells were stimulated with $A \beta$ for 24 hours. To assess the level of proinflammatory cytokine, TNF- $\alpha$, secreted after $24 \mathrm{~h}$ stimulation of microglia with $\mathrm{A} \beta$ fibril, the media from the cells was collected and analyzed using a commercially available ELISA kits ( R \& D Systems) according to the manufacturer's protocol. Cell viability was assessed by the MTT reduction assay. After 24-hour stimulation of microglia, media was removed for
ELISA and the cells were incubated with $3[4,5-$ dimethylthiazol-2-y1]-2,5-diphenyltetrazolium bromide (MTT, $100 \mu \mathrm{g} / \mathrm{mL}$ ) for 4 hours. The media was aspirated and the reduced formazan precipitate was dissolved in isopropanol. Absorbance values were read at 560/ $650 \mathrm{~nm}$ via plate reader and averaged +/- SEM.

\section{Western blot analysis of microglia cultures}

Lysates from cell stimulation experiments were diluted into sample buffer and separated via 10\% SDS-PAGE, transferred to polyvinylidene difluoride membrane and Western blotted using anti-pSrc (Tyr416), anti-pLyn (Tyr396), Src (loading control) and Lyn (loading control) and enhanced chemiluminescence for detection (GE Healthcare, Piscataway, NJ, USA). pSrc/pLyn optical densities (O.D.) from visualized Western blots were normalized to their respective loading controls (Src/Lyn) and averaged from five independent experiments.

\section{Collection of brains from different age APP/PS1 mice}

Brains from different aged APP/PS1 mice were collected for longitudinal analyses. 2-, 4-, 6- and 12-month old transgenic mice ( $n=5$ to 6 ) along with their age-matched C57BL/six wild type controls were euthanized and perfused with PBS-CaCl 2 . Brains were rapidly dissected and divided into left and right hemispheres, with right hemispheres fixed in $4 \%$ paraformaldehyde for sectioning. The left hemispheres were further dissected into different brain regions to obtain hippocampus, temporal cortex, frontal cortex and cerebellum, and flash frozen using liquid $\mathrm{N}_{2}$. The frozen tissue was lysed using RIPA with protease inhibitors and used for Western blot analysis.

\section{Subcutaneous infusions of dasatinib into APP/PS1 mice}

Dasatinib was infused subcutaneously into female APP/ PS1 mouse at 13 months of age. Dasatinib was delivered via mini-osmotic pumps (model 1004, $0.25 \mu \mathrm{L} /$ hour delivery rate, Alzet, Cupertino, CA, USA). Pumps delivered either vehicle (DMSO/Hepes) $(n=6)$ or dasatinib (500 ng/kg/day) ( $\mathrm{n}=7$ ) for 28 days. At the end of the infusion period, mice were euthanized, brains perfused with PBS- $\mathrm{CaCl}_{2}$ and rapidly collected. Control untreated APP/PS1 animals were collected at a comparable age of completion, 14 months. The right hemispheres were collected for fixing in $4 \%$ paraformaldehyde and the left hemispheres were flash frozen in liquid nitrogen for biochemical analysis.

\section{Immunostaining mouse brains}

The paraformaldehyde fixed right hemispheres for different age mice or from dasatinib treated and control mice were cut using a freezing microtome. Briefly, paraformaldehyde fixed tissue was embedded in a $15 \%$ gelatin (in $0.1 \mathrm{M}$ phosphate buffer) matrix and immersed in a $4 \%$ 
paraformaldehyde solution for two days to harden the gelatin matrix. The blocks were then cryoprotected through three cycles of $30 \%$ sucrose for three to four days each. The blocks were then flash frozen using dry ice/ isomethylpentane, and serial $40 \mu \mathrm{m}$ sections were cut using a freezing microtome. Serial sections were used for immunostaining with anti- pTyr (4G10) antibody at a dilution of 1:1,000, anti-A $\beta$ (4G8) and anti-CD68 at a dilution of 1:500 to 1:1,000, anti-pSrc as 1:250, anti-Iba1 at 1:1,000, and anti-GFAP antibody at a dilution of 1:1,000, followed by incubation with biotinylated secondary antibodies (1:2,000 dilution) (Vector Laboratories Inc.) and avidin/biotin solution (Vector $\mathrm{ABC}$ kit). The immunoreactivity was observed using Vector VIP as chromogen. For pSrc/CD68 double staining, FITC and Texas Red conjugated secondary antibodies were used. For phosphotyrosine/CD68 or Iba1 double-labeling, the sections were first immunostained with anti-phosphotyrosine antibody 4G10 using Vector VIP as the chromogen. The tissue was then incubated in $0.2 \mathrm{~N} \mathrm{HCl}$ to strip off antibodies then the tissue was double-labeled with either CD68 or Iba1 using Vector Blue as the chromogen. The slides were dehydrated and cover slipped using VectaMount (Vector Laboratories, Inc.) following a standard dehydrating procedure through a series of ethanol solutions and Histo-Clear (National Diagnostics, Atlanta, GA, USA). Images were taken using an upright Leica DM1000 microscope and Leica DF320 digital camera system (Leica Microsystems Inc., Buffalo Grove, IL, USA). Figures were made using Adobe Photoshop 7.0 software (Adobe Systems, San Jose, CA). For quantitation purposes, 1.25X images were taken from three consecutive serial sections, $(960 \mu \mathrm{m}$ apart) throughout the hippocampal region. Optical densities from the temporal cortex or CA1 regions from the same serial sections were measured using Adobe Photoshop software. All sections were immunostained simultaneously to minimize variability and background values in an unstained area of tissue for each section were set to zero using the curve tool before quantifying optical density values. The optical density of the entire temporal cortex region/CA1 region from a representative section was selected via marquee and the same size marquee was applied to all sections per condition to allow comparison of optical densities (O.D.) independent of area changes. The values for each section were averaged (three sections/ brain, five to seven brains per condition) and plotted for $A \beta$, immunoreactivity for dasatinib infusion animals, $\mathrm{pSrc}$ immunoreactivities of dastinib treated mice, and $\mathrm{A} \beta$ and CD68 immunoreactivities for longitudinal study animals. For quantitating phospho-tyrosine immunostaining from different aged APP/PS1 and wild type mice, the serial sections were viewed under a microscope and the number of $4 \mathrm{G} 10$ positive plaques were viewed from the entire CA1 and temporal cortex regions for all the animals in each condition. The numbers of plaques were averaged (three sections/brain, five to seven brains per condition) and plotted. To insure reliability in comparison, only immunostains that were processed together were quantitatively compared to minimize any variability in staining processing from day-to-day. This allows an accurate assessment of relative comparisons within parallel processed conditions and samples although not necessarily a reflection of absolute values.

\section{Western blot analyses of mouse brains}

Hippocampus and temporal cortex were removed from flash frozen brains of treated mice, lysed, sonicated in RIPA buffer and quantitated using the Bradford method [55]. The lysates were resolved using a custom-built 28well comb and 10\% SDS-PAGE and transferred to polyvinylidene difluoride membranes for Western blotting using anti-pTyr (4G10), anti-APP, anti-A $\beta$ (6E10), antiGFAP, anti-TNF- $\alpha$ and anti-CD68 antibodies with $\alpha-$ tubulin as their loading control, anti-pSrc (Tyr416), antipLyn (Tyr396) antibodies with anti-Src and anti-Lyn as their respective loading controls and anti-PSD95 and anti-synaptophysin with $\beta$ III-tubulin as the loading control. Antibody binding was detected using enhanced chemiluminescence for detection. Western blots were quantified using Adobe Photoshop software. Optical density (O.D.) of bands were normalized against their respective loading controls and averaged (+/-SEM).

\section{T-maze}

T-maze analysis was performed as described by Wenk, 1998 [56]. Briefly, upon completion of the in vivo infusion period, control and treated mice were placed into the starting arm, and the door was raised to allow animals to walk down the stem and choose an arm. Once the mice entered an arm with all four feet, they were returned to the starting arm and the door was closed. After $30 \mathrm{sec}$, the door was opened and the mice were allowed to choose an arm again. The process was repeated for nine trials with a $30 \mathrm{sec}$ interval between each trial. The choice of arms was noted each time and the number of alternations between trials for each mouse was averaged and plotted.

\section{Statistical analysis}

Data are presented as mean +/- standard deviation. Values statistically different from controls were determined using one-way ANOVA or Student $t$-test when appropriate. The Tukey-Kramer multiple comparisons post-hoc test was used to determine $P$-values. 


\section{Results}

The non-receptor tyrosine kinase inhibitor, dasatinib, decreased active-phospho Src levels in microglia BV2 cells Based upon our prior work demonstrating that both fibrillar and oligomeric $A \beta$ stimulate increased non-receptor tyrosine kinase activity in microglia [38], we determined whether a brain penetrant tyrosine kinase inhibitor, dasatinib, could attenuate activity of Src kinase in vitro. In order to validate the Src-kinase inhibitory ability of dasatinib, the mouse microglia cell line, BV2, was treated with varying concentrations of the drug. Dasatinib is a small molecule ATP-competitive inhibitor of Bcr-Abl and Src kinase with IC50s for the isolated kinases of 0.55 and $3.0 \mathrm{nM}$, respectively [57,58]. FDA-approved for use in cases of chronic phase Philadelphia chromosome-positive chronic myelogenous leukemia (CPCML), dasatinib (Sprycel, Bristol-Myers Squibb, Princeton, NJ, USA) has been shown to cross the blood-brain barrier [59]. Although dasatinib will certainly attenuate c-Abl activity, based upon limited demonstration of c$\mathrm{Abl}$ in microglia [60] and our prior work demonstrating robust $A \beta$-stimulated increase in Src family kinase activity $[38,41]$, we expected a major target of dasatinib inhibition to be the Src family of non-receptor tyrosine kinases. As expected, active, phosphorylated Src levels significantly decreased with increasing dasatinib concentrations from $1 \mathrm{nM}$ to up $1 \mu \mathrm{M}$ compared to vehicle treated BV2 cells (Figure 1). For subsequent treatments of microglial cells in vitro, a dose of $100 \mathrm{nM}$ dasatinib was chosen to obtain an optimum effect of $A \beta$ dependent tyrosine kinase inhibition in primary cultures.

Dasatinib attenuated the $A \beta$-stimulated increase in activephospho Src levels in primary murine microglia cultures

In order to determine whether dasatinib was able to reduce an $A \beta$ stimulated increase in active tyrosine kinase levels, primary microglia cultures were treated with $A \beta$ fibril with or without dasatinib. Microglial cells were pretreated with $100 \mathrm{nM}$ dasatinib followed by a five-minute stimulation by $10 \mu \mathrm{M} \mathrm{A} \beta_{\mathrm{f}}$ to detect changes in the activated, phosphorylated forms of the specific non-receptor tyrosine kinases, Src and Lyn. As expected, A $\beta$ fibrils stimulated an increase in active phospho-Src levels compared to vehicle treated cells (Figure 1). The A $\beta$ dependent increase in phospho-Src levels was significantly attenuated when cells where stimulated in the presence of dasatinib (Figure 1). Although $A \beta$ fibrils did not significantly increase the levels of active, phosphorylated Lyn kinase at the concentrations used, dasatinib was still able to significantly reduce levels of active phospho-Lyn indicating that the drug was not specific to any particular Src family member (Figure 1). In addition, the data demonstrated that the $\mathrm{A} \beta$ stimulated increase in microglial active Src kinase levels could be inhibited using a clinically relevant non-receptor tyrosine kinase Src/Abl inhibitor, dasatinib.

\section{Dasatinib attenuated A $\beta$-stimulated TNF- $\alpha$ secretion in primary microglia cultures}

In order to determine whether the $A \beta$-stimulated change in active Src levels was required for changes in phenotype, changes in secretion of the pro-inflammatory cytokine, TNF- $\alpha$, were quantified from the primary microglia cultures in the presence or absence of dasatinib. Fibrillar A $\beta$ stimulated a significant increase in TNF- $\alpha$ secretion compared to control or vehicle treated microglial cells (Figure 2). This increase in TNF- $\alpha$ secretion was attenuated by $100 \mathrm{nM}$ pretreatment of dasatinib with no effect of cellular viability (Figure 2). The data demonstrated that inhibition of Src family kinase activity was sufficient to prevent microglia from acquiring a reactive secretory phenotype upon $A \beta$ fibril stimulation in vitro.

\section{An age-dependent increase in $A \beta$ plaque density correlated with microgliosis in a transgenic mouse model of $A D$}

To determine an appropriate age in vivo for examining increased tyrosine kinase activity and $A \beta$-associated microgliosis, a transgenic APP/PS1 mouse model of AD was used. Varying age brains of APP/PS1 mice were compared to age-matched controls to validate the use of this transgenic mouse model for our study. The APP/PS1 mice were collected at 2, 4, 6 and 12 months of age along with their age-matched wild type mice (C57BL/6) and brains were sectioned for histology. Immunostaining demonstrated a significant increase in APP/PS1 temporal cortex CD68 immunoreactivity in 6- and 12-month old mice compared to earlier 2- and 4-month APP/PS1 age groups and their age-matched C57BL/6 controls (Figure 3). This increase correlated precisely with increased plaque-associated $A \beta$ immunoreactivity in the 6- and 12-month old APP/PS1 mice (Figure 3). Analyses of hippocampi from all groups showed similar results to the temporal cortex (data not shown). These data supported the notion that microglial activation in $\mathrm{AD}$ and its mouse models may be a consequence of $A \beta$ fibril interaction. However, to validate an involvement of tyrosine kinase activity in microglial phenotype changes during disease, APP/PS1 brains were next immunostained with anti-phosphotyrosine antibody as an indirect method to assess overall tyrosine kinase activity changes. Immunostaining mouse brains with antiphosphotyrosine antibody, 4G10, demonstrated positive microglial-like as well as vascular immunoreactivity (Figure 4). Microglial-like immunoreactivity increased in intensity demonstrating transition from ramified to a more compact, plaque-clustered morphology with increasing age in APP/PS1 mice compared to controls 

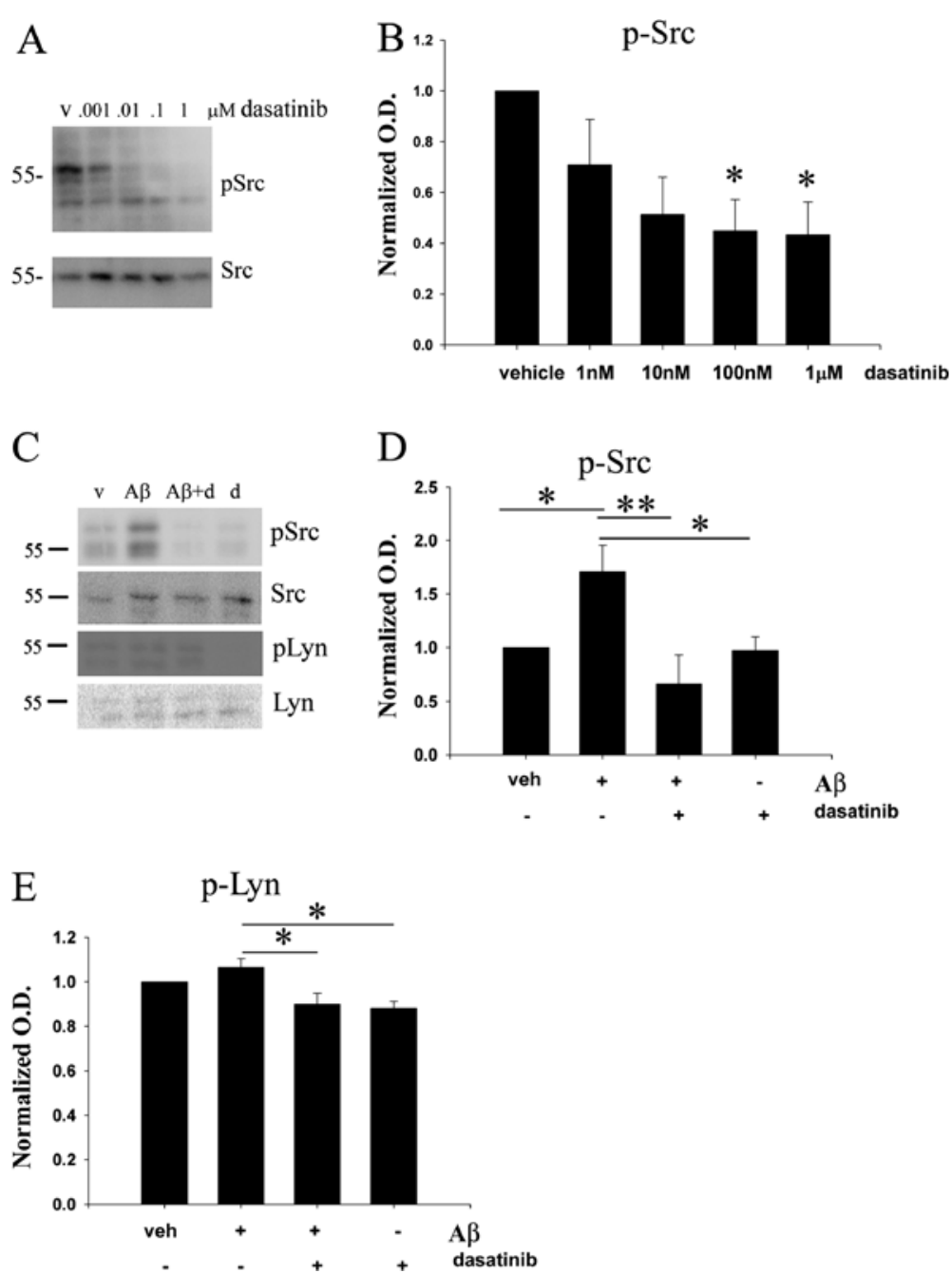

Figure 1 Dasatinib dose-dependently attenuated active, phospho-Src kinase levels in the BV2 cell line and primary microglia. (A) Microglial BV2 cells were vehicle treated (v), or treated with $1 \mathrm{nM}, 10 \mathrm{nM}, 100 \mathrm{nM}$ and $1 \mu \mathrm{M}$ dasatinib for 30 minutes. Cells lysates were resolved by SDS-PAGE and Western blotted using anti-phospho-Src, and Src antibodies. (B) Densitometric analyses of the Western blots were performed normalizing active-Src levels against their respective Src controls and averaging +/-SEM. Blots are representative of six independent experiments. Primary microglia were DMSO vehicle treated (veh), or stimulated for 5 minutes with $10 \mu \mathrm{M}$ A $\beta_{f}$ in the presence or absence of 30-minute pretreatment of $100 \mathrm{nM}$ dasatinib. (C) Cells lysates were Western blotted using anti-pSrc or Src (loading control) antibodies and anti-pLyn or Lyn (loading control) antibodies. A representative blot from six independent experiments is shown. Densitometric analyses of the Western blots was performed normalizing (D) active, phospho-Src levels against Src controls and (E) active, phospho-Lyn levels against Lyn controls and averaging + +-SEM. Percent fold changes in phospho-Src and phospho-Lyn levels were plotted. ${ }^{*} P<0.05$ vs. vehicle, dasatinib, ${ }^{*} P<0.01$ vs. A $\beta+$ dasatinib for $p S r c$ and ${ }^{*} P<0.01$ vs. A $\beta$ for $\left.p L y n\right)$.

(Figure 4). Counting plaque-associated, 4G10 positive staining as putative microglia demonstrated a trend of age-associated increase in APP/PS1 temporal cortex staining with a significant increase by 4 months of age with significantly higher immunoreactivity at 6 and 12 months (Figure 4). Similar trends were observed in the hippocampus (data not shown). To validate that phosphotyrosine immunoreactivity partially co-localized to microglia, sections were double-labeled with both antiphosphotyrosine antibody and anti-CD68 or antiIba1 antibodies. Double-labeling demonstrated that a portion of the phosphotyrosine immunoreactivity demonstrated clear co-localization with either microglial marker, CD68 or Iba1 (Figure 4). These data confirmed that by 12 months of age, this particular transgenic line had robust phosphotyrosine microglial reactivity in association with $A \beta$ plaques providing us with the appropriate time point for use. 


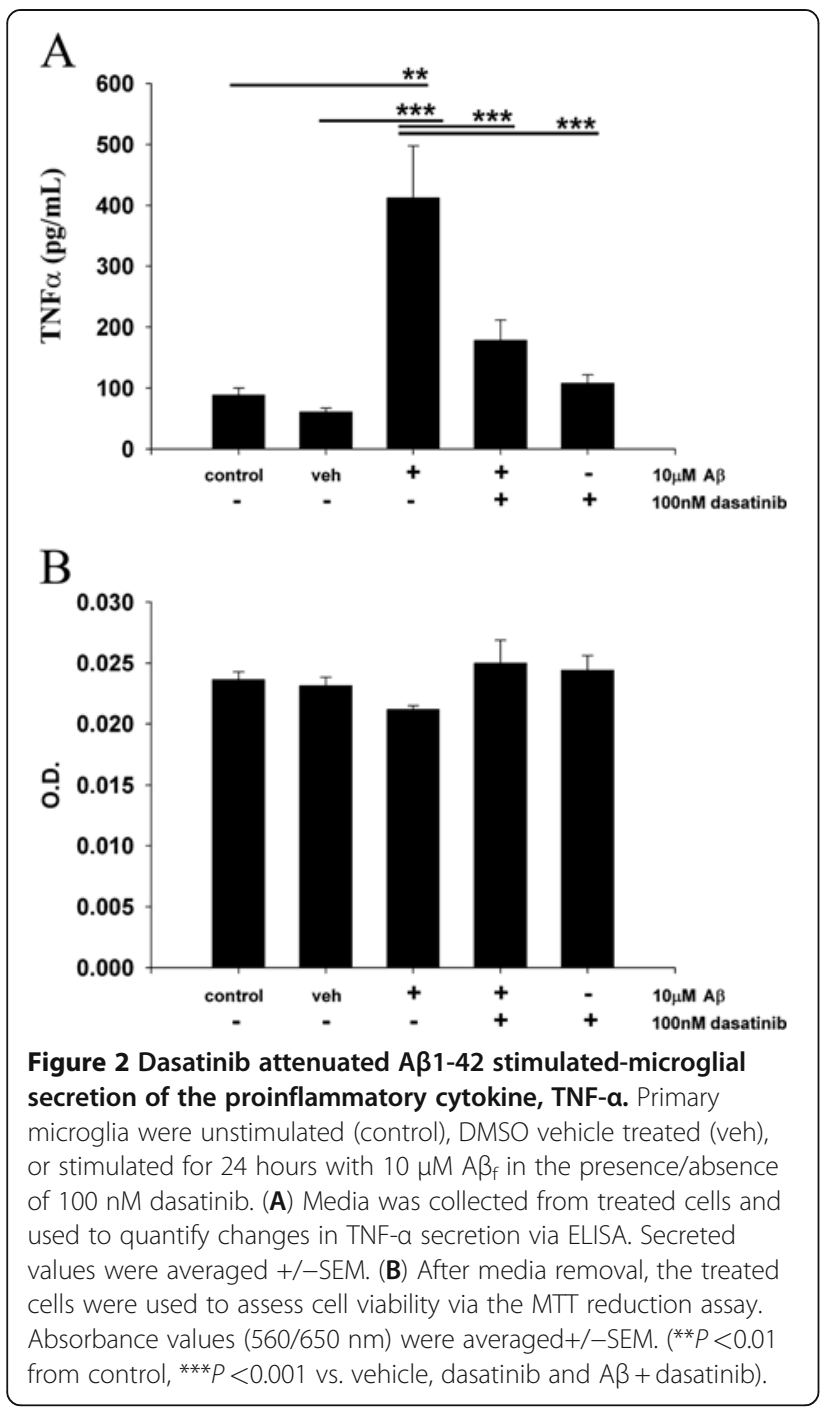

\section{Dasatinib infusion decreased phospho-Src but not phospho-Lyn levels in APP/PS1 mice}

Based upon the temporal profiling of microgliosis we next determined whether inhibition of tyrosine kinase activity could attenuate the microglial reactivity in this line. Based upon our in vitro data we hypothesized that dasatinib treatment would attenuate the $\mathrm{A} \beta$-associated increase in tyrosine kinase activity, particularly Src, and subsequent inflammatory changes in the mice. In order to answer this question, 13 month old APP/PS1 female mice were subcutaneously infused with dasatinib or vehicle for 28 days. Dasatinib infusion significantly decreased protein phosphotyrosine levels in the hippocampus but not the temporal cortex compared to vehicle infused control animals (Figure 5). More importantly, dasatinib infusion significantly decreased levels of active, phospho-Src in both temporal cortex and hippocampus compared to control mice (Figure 5). However, dasatinib infusion had no effect on the active, phosphorylated levels of the related Src family member, Lyn kinase, demonstrating some specificity of the drug (Figure 5). These data demonstrated that a subcutaneous route of dasatinib delivery was able to inhibit levels of active Src in the brains of the APP/PS1 mice.

\section{Dasatinib infusion decreased TNF-a levels and microgliosis in APP/PS1 mice}

Based upon the encouraging findings that dasatinib was able to exert brain effects and decrease active Src levels, we expected that dasatinib infusion should also attenuate microgliosis and TNF $\alpha$ secretion as observed in our in vitro findings. Dasatinib infusion significantly decreased TNFa levels in both the hippocampus and temporal cortex correlating with the decrease in active Src levels and demonstrating a clear brain anti-inflammatory effect of the drug (Figure 6). Moreover, levels of CD68, the reactive microglial marker protein, were significantly decreased in the hippocampus of dasatinib infused brains but not the temporal cortex. These data demonstrated that dasatinib inhibition of brain active Src levels correlates with a significant anti-inflammatory, microglial-inhibitory effect in APP/PS1 mice. Interestingly, these effects appeared most robust in the hippocampus compared to the temporal cortex (Figure 6).

\section{Dasatinib infusion did not alter $A P P, A \beta$, or synaptic protein levels in APP/PS1 mice}

To examine the breadth of changes that might result from dasatinib infusion we also determined whether adverse effects on neurons, astrocytes, or $\mathrm{A} \beta$ deposition resulted from drug treatment in addition to the anti-inflammatory, microglial-inhibitory changes. However, dasatinib administration had no effect on either total APP levels or A $\beta$ levels in the hippocampus or temporal cortex of treated mice compared to vehicle controls (Figure 7). In addition, dasatinib treatments did not increase levels of the reactive astrocyte marker protein, GFAP, in the infused animals compared to vehicle control mice (Figure 7). Finally, dasatinib treatment did not have any significant effects on levels of either presynaptic, synaptophysin, or post-synaptic, PSD 95, proteins in either the temporal cortex or hippocampus compared to vehicle treated mice (Figure 7). These data demonstrated that the Src inhibitory, anti-inflammatory, microglia-inhibitory effects of dasatinib treatment did not correlate with any robust adverse effects such as increased astrogliosis, neuron or synaptic loss, and increased $A \beta$ deposition.

Dasatinib infusion decreased immunoreactivity of protein phosphotyrosine, phospho-Src and CD68 in APP/PS1 mice To provide qualitative assessments along with the quantitative Western blot analyses, select immunohistochemical studies were also performed from the treated 


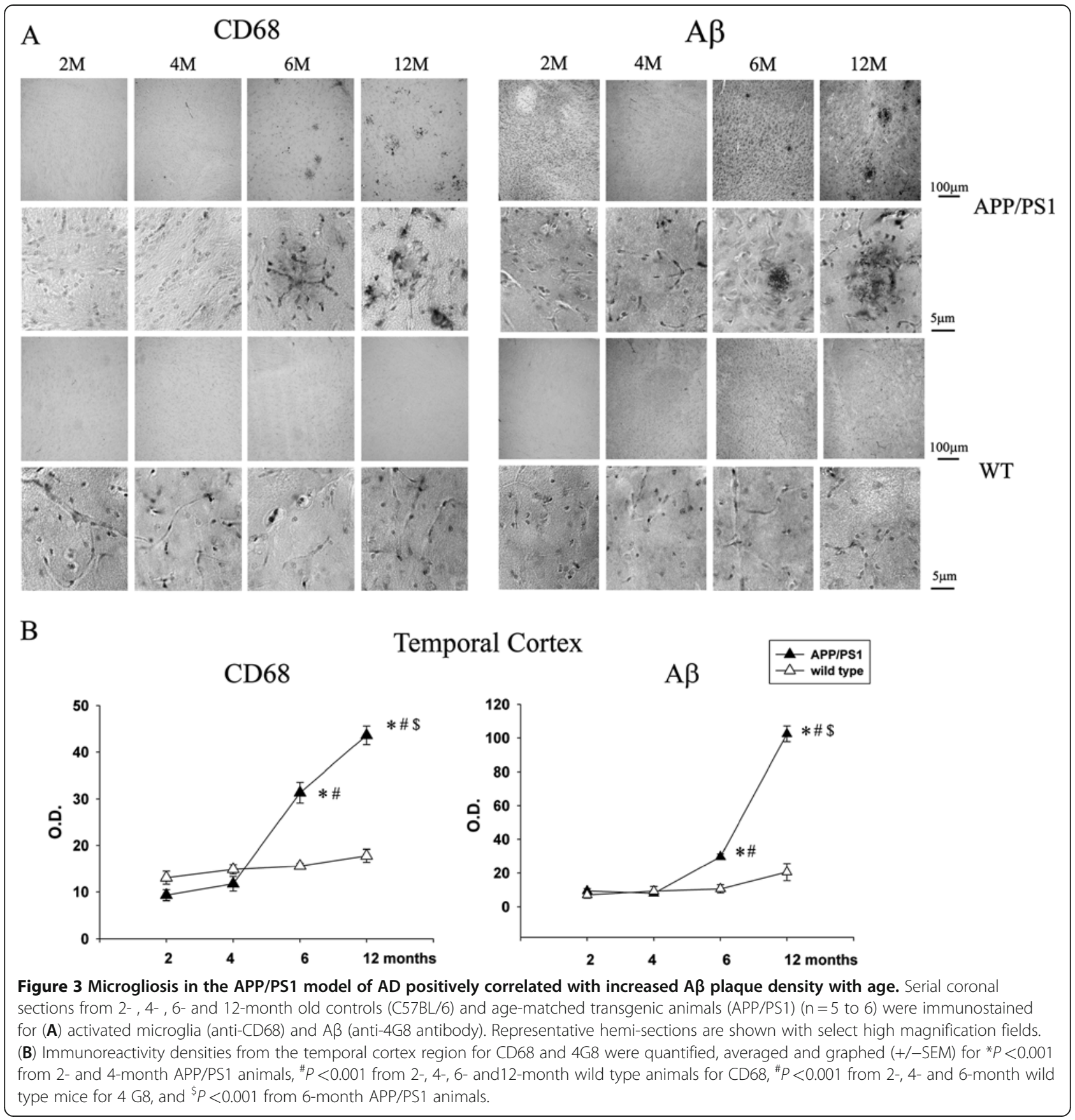

animals. As expected, protein phosphotyrosine immunoreactivity in dasatinib infused mouse brains appeared dramatically less than vehicle treated mice in both the hippocampus and temporal cortex (Figure 8). A similar trend of dasatinib decreased immunoreactivity was observed for active phospho-Src versus vehicle controls (Figure 8). Similar to phosphotyrosine, pSrc immunoreactivity also localized to vasculature as well as microglial-like immunoreactivity (Figure 8). Double-labelling verified that a portion of the pSrc immunoreactivity colocalized to microglia (Figure 8). Because the majority of
pSrc immunoreactivity was observed in plaque-associated microglial-like cells we suggest that the significant decreases in active Src and phosphotyrosine levels observed by Western blot analyses were a reflection of microglial changes due to the drug. However, certainly a portion of both phosphotyrosine and pSrc level changes detected by the Western blot analyses is due to contributions from cells other than microglia. Also as predicted, levels of CD68 reactive microglial immunoreactivity in dasatinib infused mice was noticeably decreased compared to vehicle treated mice in both the hippocampus 


\section{phospho-Tyrosine (4G10)}
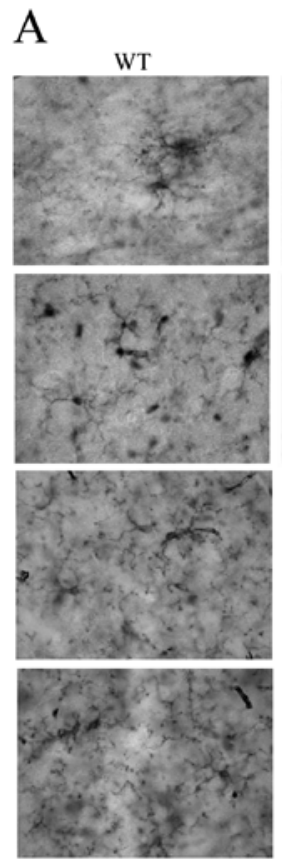

APP/PS1
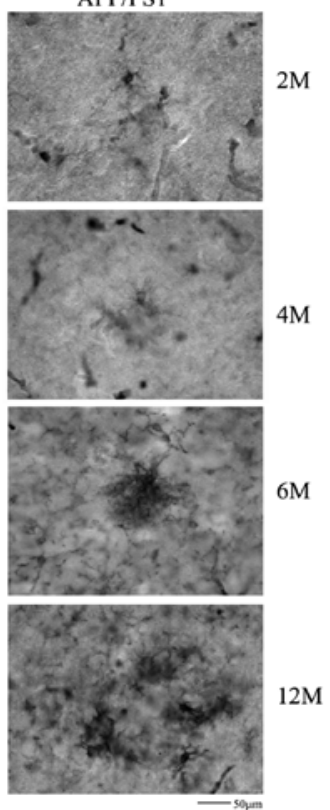

$6 \mathrm{M}$
B

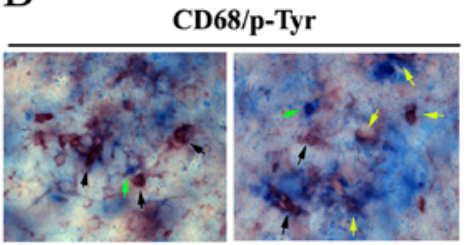

Iba1/p-Tyr

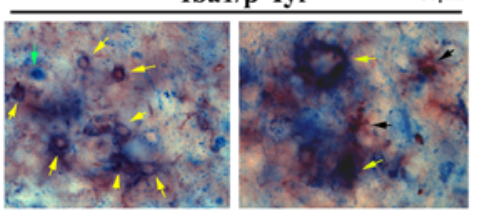

C

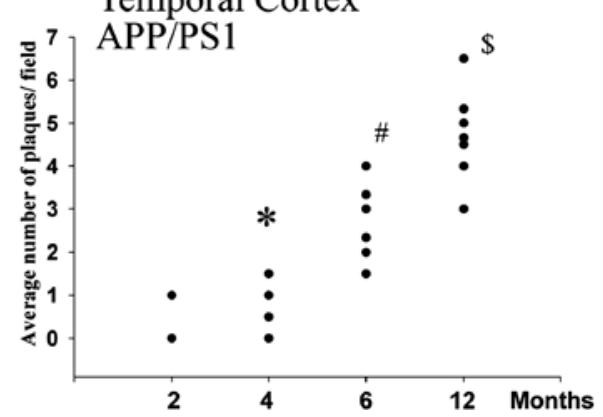

Figure 4 Plaque-associated microglial phosphotyrosine immunoreactivity increased with age in APP/PS1 mice. (A) Serial coronal sections from 2-, 4-, 6- and 12-month-old controls (C57BL/6) and age-matched transgenic animals (APP/PS1) ( $\mathrm{n}=5$ to 6) were immunostained with antiphosphotyrosine antibody (4G10). Representative select high magnification fields from the temporal cortex of hemisections are presented. (B) To validate microglial co-localization of phospho-tyrosine immunoreactivity, 12-month APP/PS1 sections were double-labeled using antiphosphotyrosine antibodies and VIP as the chromogen (black arrows) and anti-CD68 or lba1 and Vector Blue as the chromogen (green arrows). Double-labeled cells are indicated with yellow arrows. (C) To quantify immunoreactivity and omit the inclusion of non-microglial phosphotyrosine immunoreactivity, 4G10 positive plaques from APP/PS1 mice were counted from the temporal cortex and averaged and graphed (+/-SEM) for ${ }^{*} P<0.001$ from two-month APP/PS1 mice, ${ }^{\#} P<0.001$ from two-month and four-month APP/PS1 animals, $\$ P<0.001$ from four- and six-month APP/ PS1 animals.

and temporal cortex (Figure 8). Consistent with the Western blot analysis, GFAP immunoreactivity for reactive astrocytes was not visually different between dasatinib and vehicle infused mice in either temporal cortex or hippocampus (Figure 8). The qualitative immunostaining findings corroborated the quantitative Western blot analyses and suggest that the significant decreases in pSrc levels were largely due to decreased microglial immunoreactivity, our intended target for the drug.

\section{$A \beta$ plaque load was not affected by dasatinib infusions into the APP/PS1 mice}

One possible consequence of attenuated tyrosine kinase activity in microglia could be inhibition of phagocytic ability. It is well known, for instance, that tyrosine kinase activity can affect macrophage phagocytic ability [61-63]. Therefore, inhibition of Src or related kinase activity might attenuate any ability microglia have to clear $A \beta$ deposits in the brain producing an unwanted side-effect of increased plaque load. Based upon the Western blot analysis, dasatinib treatment had no effect on altering APP or A $\beta$ levels in the brains of mice (Figure 8). However, to better assess whether the drug had any effects on insoluble fibrillar deposits in the brain, quantitative immunostaining of $A \beta$ plaques was performed. Dasatinib treatment had no effect on plaque load in treated mice compared to vehicle controls in either the hippocampus or temporal cortex (Figure 9). These data demonstrate that the microglial-inhibitory effects of dasatinib do not result in unwanted effects of increasing $A \beta$ deposition or accumulation.

\section{Dasatinib infusion improved $\mathrm{T}$ maze performance in APP/PS1 mice}

Although there was no effect of dasatinib treatment on A $\beta$ deposition, the clear and somewhat specific effect of Src inhibition correlating with anti-inflammatory, microglial-inhibitory effects provided an opportunity to assess 


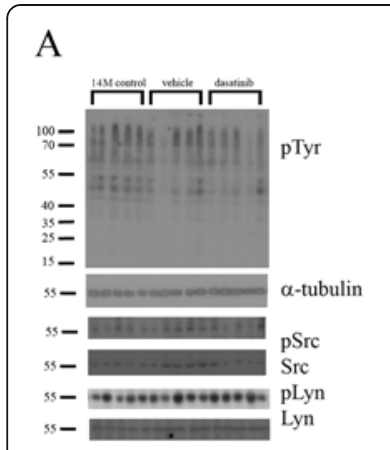

\section{Hippocampus}
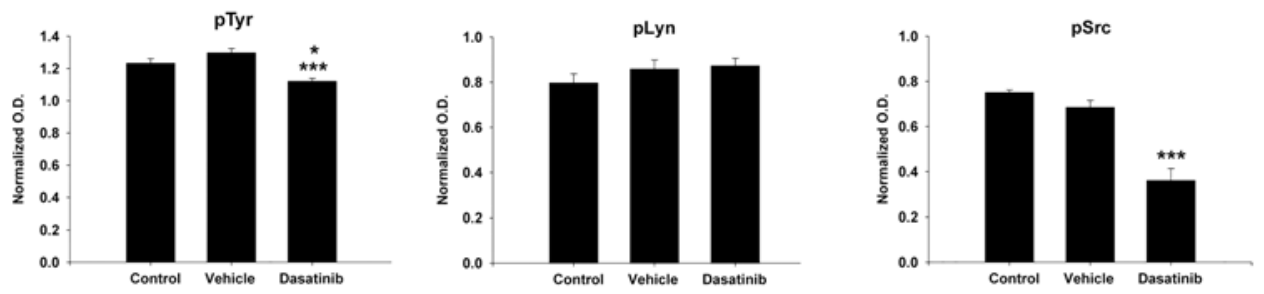

B

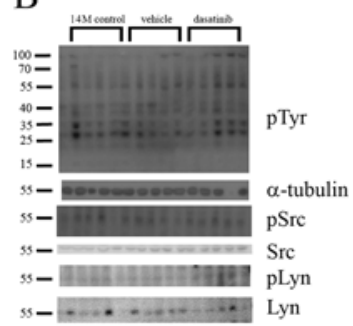

D

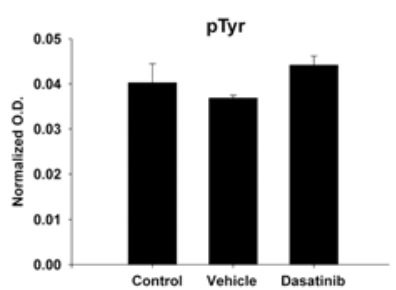

Temporal Cortex

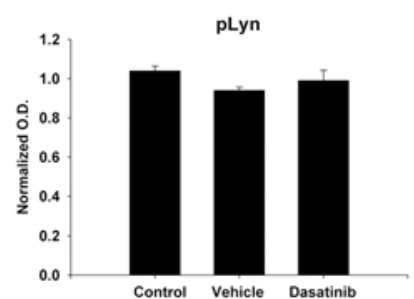

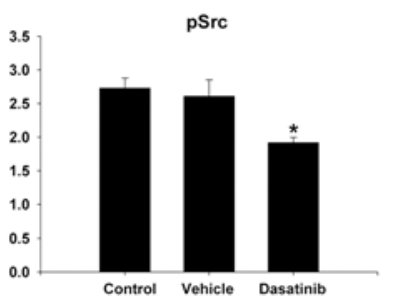

Figure 5 Dasatinib infusion reduced protein phospho-tyrosine and active phospho-Src kinase levels in APP/PS1 brains. Vehicle or dasatinib (500 ng/kg/day) was infused subcutaneously into 13-month-old APP/PS1 for 28 days ( $\mathrm{n}=7$ ). Hippocampus and temporal cortex regions were dissected from the left hemispheres and resolved by 10\% SDS-PAGE and Western blotted. (A) Hippocampal and (B) temporal cortex brain lysates from control (14-month APP/PS1), vehicle infused, and dasatinib infused animals were blotted using anti-phosphotyrosine, pTyr (4G10), pSrc, pLyn, a-tubulin, Src, and Lyn antibodies. Optical densities were averaged and graphed (+/-SEM) from blots of (C) hippocampus (*P <0.05 from controls, ${ }^{* *} P<0.001$ from vehicle) and (D) temporal cortex. ( ${ }^{*} P<0.05$ from controls).

whether dasatinib could also provide cognitive improvement to the mice. After treatments, spontaneous alternations from dasatinib treated, vehicle treated and control animals were quantified during $\mathrm{T}$ maze analyses. This particular model of spatial memory was selected based upon its sensitivity of detection of cognitive deficit in AD mouse models [64] and its preference for detecting changes in hippocampal-based performance differences $[65,66]$ since our most significant effects of drug were observed in the hippocampus. Dasatinib infused animals demonstrated improved cognitive performance represented by a significant increase in spontaneous alternations compared to vehicle treated mice (Figure 10). These data validated that subcutaneous administration of the Src/Abl tyrosine kinase inhibitor, dasatinib, is able to provide cognitive enhancing effects to APP/PS1 mice while attenuating microglial activation and proinflammatory cytokine, TNF $\alpha$, levels in the brain.

\section{Discussion}

Our findings demonstrated that $A \beta$ fibrils stimulate microglia activation in vitro via a non-receptor tyrosine kinase, Src, associated pathway that results in increased secretion of the proinflammatory cytokine, TNF- $\alpha$. It was possible to attenuate the $A \beta$-stimulated microglial phenotype change using a dual Src/Abl inhibitor, dasatinib. The in vitro observations were validated in vivo demonstrating that subcutaneous infusion of dasatinib into 13 month old APP/PS1 transgenic mice attenuated overall tyrosine phosphorylation and active Src levels, in particular, in the hippocampus. The drug did not affect A $\beta$ plaque load but reduced microgliosis and TNF- $\alpha$ levels in these animals without altering synaptic markers in neurons. Moreover, dasatinib provided a significant increase in cognitive performance in correlation with this anti-inflammatory action. Collectively, these findings support the idea that $A \beta$ fibrils can serve as a microglial activating ligand in disease contributing to their proinflammatory phenotype and use of selective non-receptor tyrosine kinase inhibitors is an effective strategy to limit microglial-mediated changes during disease.

Although it has been suggested that $A \beta$-stimulated microglial activation contributes to the pathophysiology of $\mathrm{AD}$ [24-26,28-30,33,67] and a broad range of microglial secreted inflammatory markers are elevated in AD brains, including IL- $\alpha$, IL- $1 \beta$, TGF- $\beta$ and TNF- $\alpha$ $[68,69]$, enthusiasm for an anti-inflammatory approach to treating $\mathrm{AD}$ has decreased, in part, due to lack of drug efficacy of a number of human trials that targeted cyclooxygenase (Cox) activity in AD patients [70-74]. Indeed, Cox inhibition during later stages of disease had adverse effects and only demonstrated protection when administered long-term to asymptomatic individuals [37]. One possibility for the lack of efficacy of Cox 


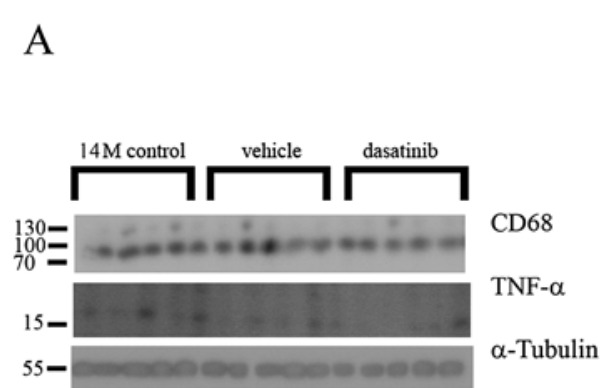

B

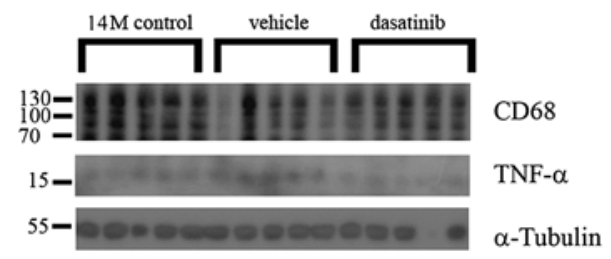

C Hippocampus
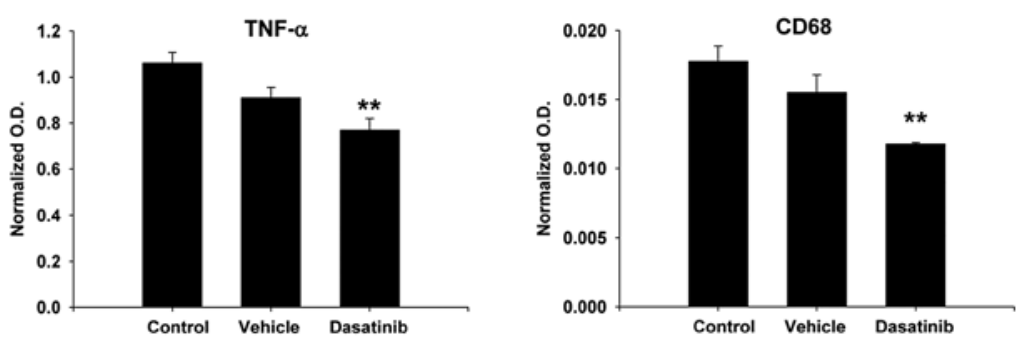

D Temporal Cortex
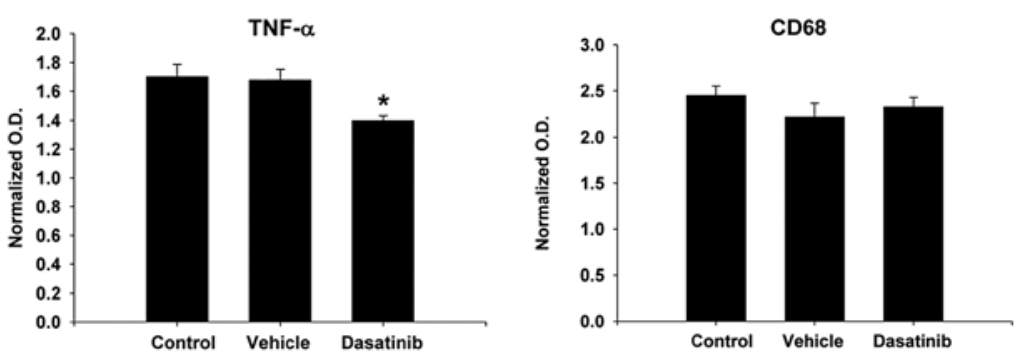

Figure 6 Dasatinib infusion reduced CD68 and TNF-a protein levels in APP/PS1 brains. (A) Hippocampal and (B) temporal cortex brain lysates from control, vehicle, and dasatinib infused animals were Western blotted for activated microglia using anti-CD68 antibody and anti-proinflammatory cytokine TNF-a antibody along with anti-a-tubulin as a loading control. Optical densities were averaged and graphed (+/-SEM) from blots of $(\mathbf{C})$ hippocampus ( ${ }^{*} P<0.01$ from controls) and (D) temporal cortex $\left({ }^{*} P<0.05\right.$ from controls).

inhibitors is the fact that Cox enzymes are expressed by multiple cell types in the brain and general drug inhibition has no cellular selectivity. Another possibility for the failed efficacy is that Cox 1 or 2 enzyme activities are simply not relevant targets for attenuating microgliadependent changes. For this reason we focused on the direct signaling response initiated in microglia upon $A \beta$ fibril stimulation. It has been reported from both $\mathrm{AD}$ brains [75-77] and mouse models [13,78] that elevated protein phosphotyrosine levels are reliable markers of reactive microglia associated with plaques. In vitro studies using monocytic lineage cells $[24,44,47]$ and microglia $[38,41]$ have supported these data by demonstrating that fibrillar $A \beta$ stimulates a specific increase in overall protein tyrosine phosphorylation. Based upon our in vitro data, we targeted Src as a key enzyme activated downstream of $A \beta$ fibril stimulation and demonstrated that a clinically available drug, dasatinib, was able to improve cognitive function while attenuating microglial activation and active Src levels in these cells. Importantly, this antiinflammatory effect did not adversely affect $A \beta$ plaque load in the mice. Therefore, a directed anti-inflammatory strategy targeting the particular enzymes involved in $A \beta-$ stimulated microgliosis may be more relevant than broad-based Cox inhibition for testing during disease. Moreover, the fact that this tyrosine kinase inhibition strategy was effective even during advanced stages of disease in the mice suggests that this particular form of anti-inflammatory therapy is viable during advanced disease in contrast to Cox inhibition.

We are aware that the effect of decreasing microglial active Src and brain TNF $\alpha$ levels does not necessarily prove that these changes were responsible for the improved cognitive performance. However, our in vitro data clearly demonstrated that dasatinib treatment and Src inhibition led to attenuated TNF $\alpha$ secretion providing correlative evidence that Src inhibition in microglia in vivo contributed to the decrease in TNF $\alpha$ observed. Moreover, recent human data using TNF $\alpha$ neutralizing drugs demonstrated cognitive improvement in AD patients [79] suggesting that diminished TNF $\alpha$ levels in the mice could have contributed to the cognitive improvements observed.

We also appreciate that dasatinib treatment may affect a number of other kinases in vitro and in vivo, and numerous cells express Src family kinases and Abl. Nonreceptor Src family tyrosine kinases are expressed widely in the mammalian CNS and are known to play a role in proliferation and differentiation of the CNS [80-89]. Indeed, Src family kinase activities are crucial for synaptic plasticity, including learning and memory [90-94]. Additionally, there is compelling evidence that neuronal $\mathrm{Abl}$ activity can also mediate microgliosis in vivo, suggesting that dasatinib may also work through this mechanism to exert its anti-inflammatory effects [60]. It is also intriguing that $\mathrm{Abl}$ is able to phosphorylate tau protein on 


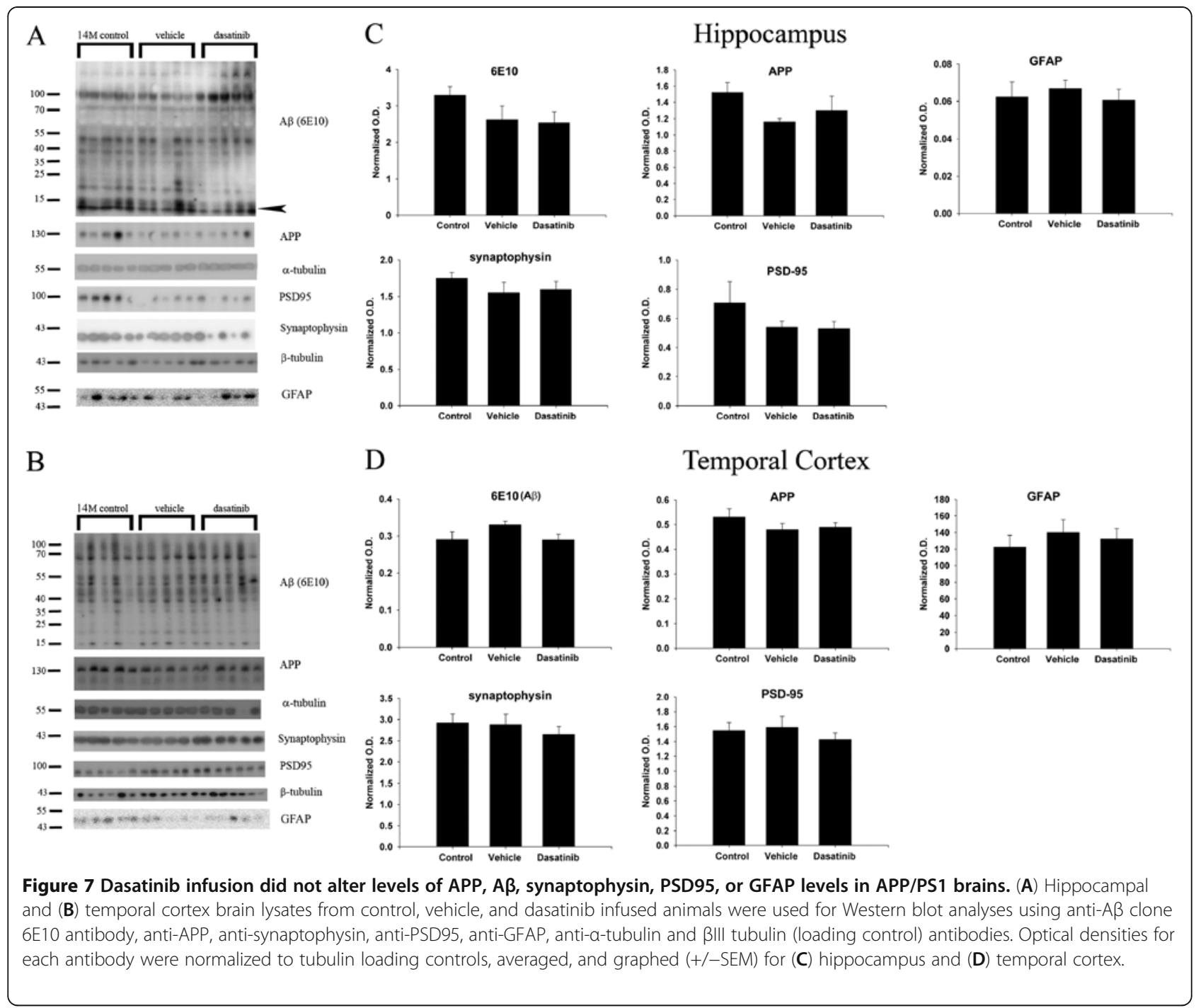

Tyr 394 identified from AD brains as well as the intracellular domain of APP to modulate signaling responses [95-97]. Although we have not focused on Abl expression or activity in this study we appreciate that activity of this kinase is of great interest to not only the field of AD but myriad conditions in which oxidative stressassociated neuron death is involved, including Parkinson's disease [60,96,98-102]. However, this interest in Abl activity to regulate cell death [60], parkin phosphorylation $[99,100]$ and tau phosphorylation $[98,101,102]$ is all based upon neuronal expression of the kinase. Indeed, there is no reported expression of Abl in microglia, to the best of our knowledge. We expect that dasatinib actions in the brain will certainly include inhibition of not only microglial Src activity but additional Src family members expressed in microglia and other cells as well as Abl, which will have a broader target base than only a single kinase activity in microglia. This may have additional therapeutic benefits of not only anti-inflammatory actions on microglia but also direct neuroprotection. We do not rule out that some of the changes we observed are not also due to inhibition of Src family kinases or other non-receptor kinases, including $\mathrm{Abl}$ in our experiments. Certainly, our staining demonstrated additional vasculature phospho-tyrosine and pSrc immunoreactivity outside of the microglial immunoreactivity. Therefore, any strategy to manipulate activity of these tyrosine kinases in the brain should be carefully considered with regard to particular cellular targets. By focusing on microglia- $\mathrm{A} \beta$ interaction and demonstrating specificity of dasatinib for Src versus the related family member Lyn in vivo as well as a clear improvement in cognitive performance, we suggest that reagents, such as dasatinib, at least be considered for anti-inflammatory human testing but, more importantly, for further drug development. 


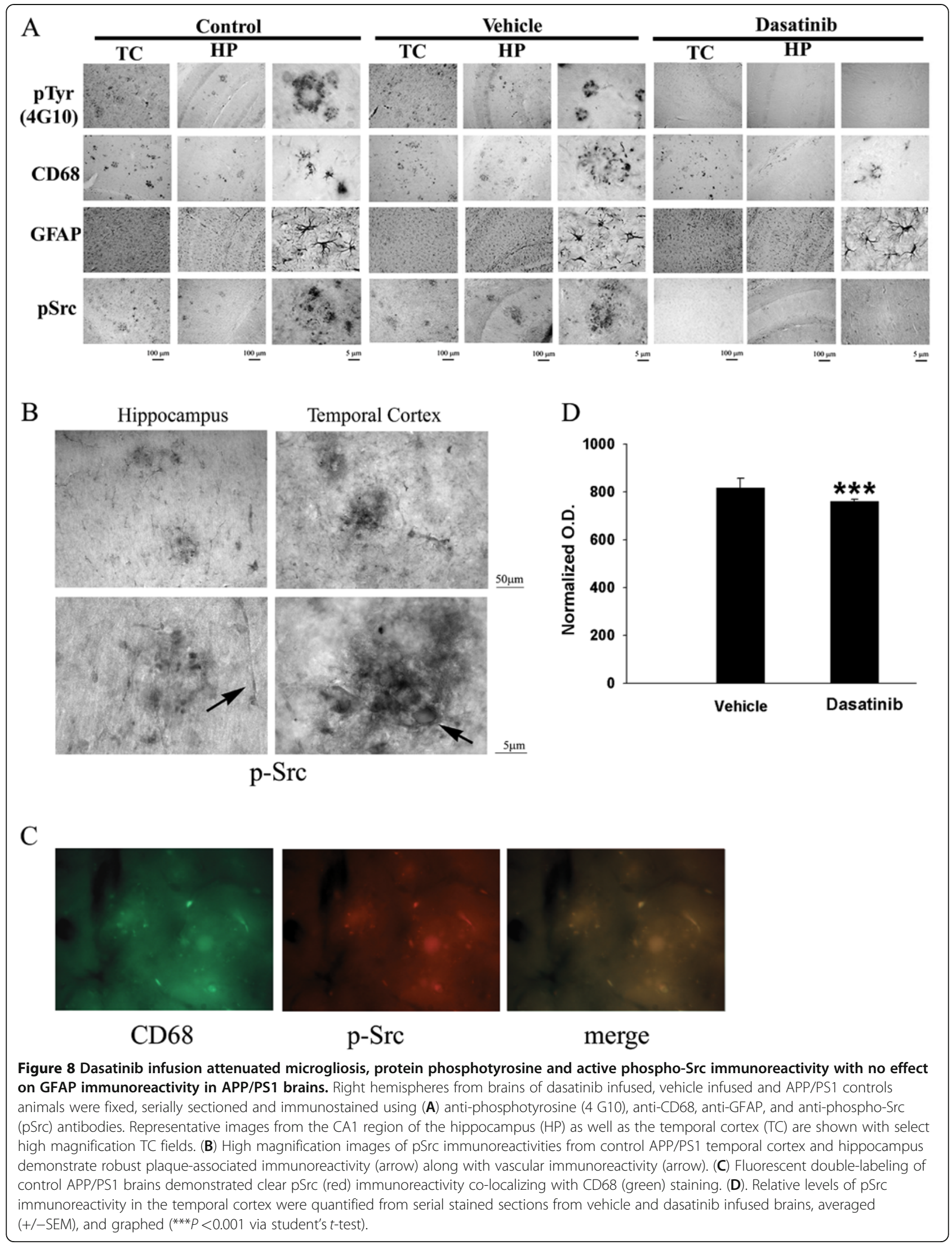




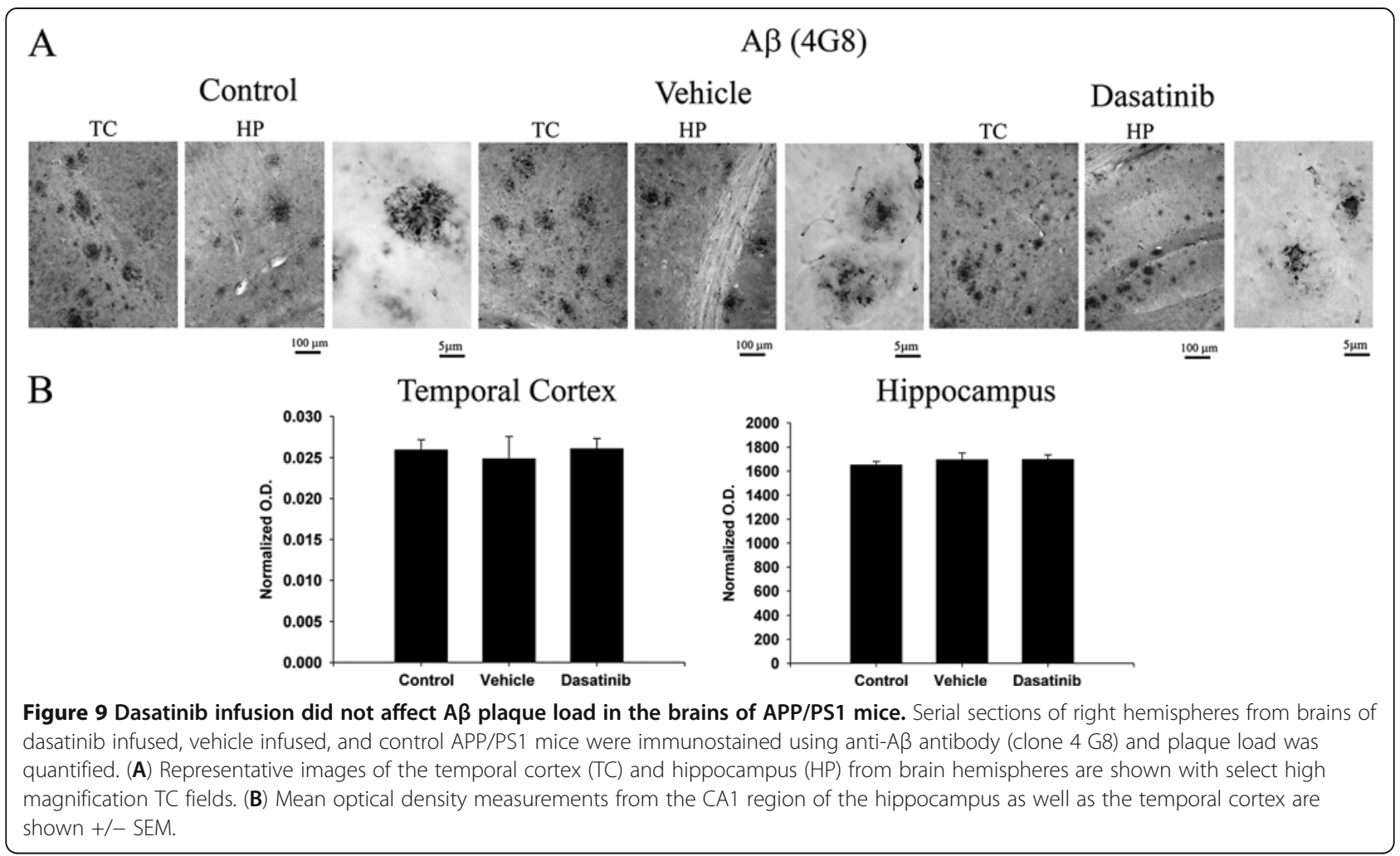

Our study intentionally focused on animals at 13 months of age with established plaques and reactive microglia to test the efficacy of our anti-inflammatory strategy in late-stage disease. However, it will be important in future work to determine if a strategy of kinase inhibition can attenuate or delay behavioral decline or microgliosis in earlier stage disease. Although our

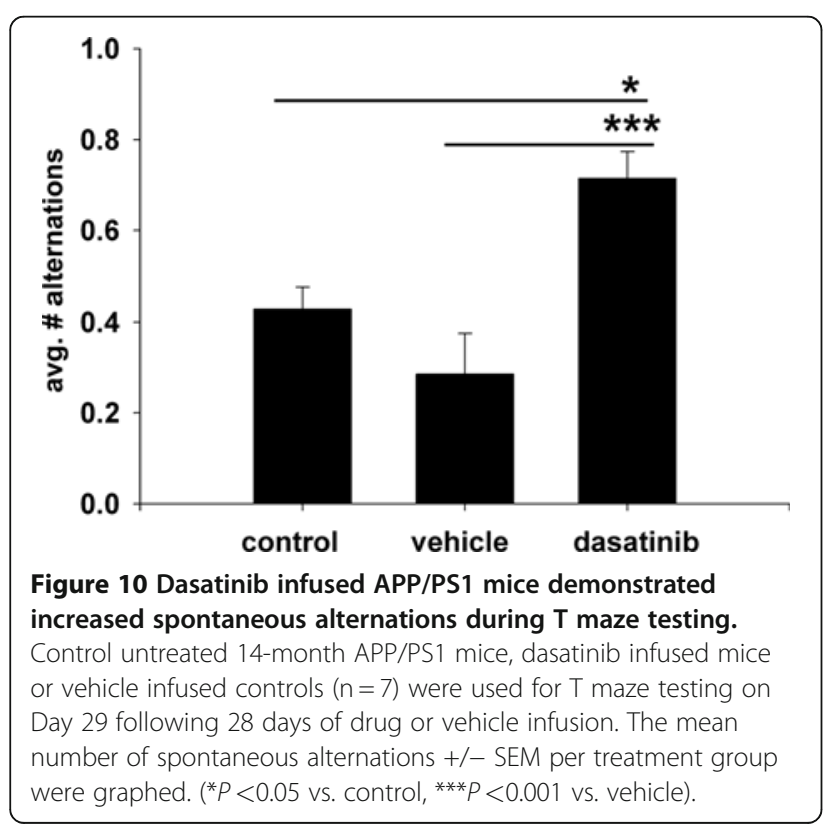

longitudinal assessment in these mice suggested that phosphotyrosine immunoreactive microglia correlated with increased plaque deposition, we have observed in earlier work that soluble oligomeric forms of $A \beta$ are also potent stimuli of microglia responsible for initiating a unique type of tyrosine kinase-based signaling response [38]. Therefore, fully determining the specific signaling pathways involved in different forms of $A \beta$ stimulation of microglia may offer a strategy for inhibiting specific tyrosine kinase activities at different disease time points to maximally produce anti-inflammatory effects.

\section{Conclusions}

These data demonstrate that the mechanism underlying amyloid-dependent microgliosis in $\mathrm{AD}$ may involve increased Src family kinase activity. We targeted this specific signaling response with dasatinib, a dual Src/Abl inhibitor used for treatment of chronic myeloid leukemia $[103,104]$ For the first time, we have found that dasatinib treatment not only attenuated microgliosis, TNF $\alpha$ levels, and active Src levels in the brains of APP/PS1 mice but also improved cognitive performance. This suggests that targeting the specific enzymes involved in A $\beta$-stimulated microglial activation may be efficacious therapeutically even during late stages of disease.

AD, Alzheimer's Disease; A $\beta$, amyloid beta; APP, amyloid precursor protein; GFAP, glial fibrillary acidic protein; Iba1, ionized calcium binding adaptor molecule 1; 
PSD95, postsynaptic density protein 95; TNFa, tumor necrosis factor $\alpha$.

\section{Competing interests}

The authors declare that they have no competing interests.

\section{Acknowledgements}

This work was supported by NIHRO1AG026330 to C.K.C. and NSF grant \# EPS0814442 to G.D. The authors would like to thank Ms. Angela Floden for help with animal surgeries. The authors would also like to thank Mr. Jack Chatt for producing the multi-well mini-gel combs for SDS-PAGE analysis.

\section{Author details}

'Department of Pharmacology, Physiology and Therapeutics, University of North Dakota, Grand Forks, ND 58203, USA. ${ }^{2}$ School of Medicine and Health Sciences, 504 Hamline St., Room 118, Grand Forks, ND 58203, USA.

\section{Authors' contributions}

GD performed the majority of experiments and data analysis, and wrote the initial version of the manuscript. CC was involved in conceiving the study, performing a portion of the experiments and analysis, and coordinating the experiments. He was responsible for editing and revising the final version of the manuscript. All authors read and approved the final manuscript.

Received: 28 September 2011 Accepted: 6 June 2012

Published: 6 June 2012

\section{References}

1. Akiyama H, Mori H, Saido T, Kondo H, Ikeda K, McGeer PL: Occurrence of the diffuse amyloid beta-protein (Abeta) deposits with numerous Abetacontaining glial cells in the cerebral cortex of patients with Alzheimer's disease. Glia 1999, 25:324-331.

2. Benzing WC, Wujek JR, Ward EK, Shaffer D, Ashe KH, Younkin SG, Brunden KR: Evidence for glial-mediated inflammation in aged APP(SW) transgenic mice. Neurobiol Aging 1999, 20:581-589.

3. Itagaki S, McGeer PL, Akiyama H, Zhu S, Selkoe D: Relationship of microglia and astrocytes to amyloid deposits of Alzheimer disease. J Neuroimmunol 1989, 24:173-182.

4. Mattiace LA, Davies P, Dickson DW: Detection of HLA-DR on microglia in the human brain is a function of both clinical and technical factors. Am J Pathol 1990, 136:1101-1114.

5. Mackenzie IR, Hao C, Munoz DG: Role of microglia in senile plaque formation. Neurobiol Aging 1995, 16:797-804.

6. Perlmutter LS, Barron E, Chui HC: Morphologic association between microglia and senile plaque amyloid in Alzheimer's disease. Neurosci Lett 1990, 119:32-36.

7. Sasaki A, Yamaguchi H, Ogawa A, Sugihara S, Nakazato Y: Microglial activation in early stages of amyloid beta protein deposition. Acto Neuropathol 1997, 94:316-322.

8. Mever-Luehmann M, Spires-Jones TL, Prada C, Garcia-Alloza M, de Calignon A, Rozkalne A, Koenigsknecht-Talboo J, Holtzman DM, Bacskai BJ, Hyman BT: Rapid appearance and local toxicity of amyloid-beta plaques in a mouse model of Alzheimer's disease. Nature 2008, 451:720-724.

9. Morgan D, Gordon MN, Tan J, Wilcock D, Rojiani AM: Dynamic complexity of the microglial activation response in transgenic models of amyloid deposition: implications for Alzheimer therapeutics. J Neuropathol Exp Neurol 2005, 64:743-753.

10. McGeer PL, Itagaki S, Tago H, McGeer EG: Reactive microglia in patients with senile dementia of the Alzheimer type are positive for the histocompatibility glycoprotein HLA-DR. Neurosci Lett 1987, 79:195-200.

11. Akiyama H, McGeer PL: Brain microglia constitutively express beta-2 integrins. J Neuroimmunol 1990, 30:81-93.

12. Cras P, Kawai M, Siedlak S, Mulvihill P, Gambetti P, Lowery D, GonzalezDeWhitt P, Greenberg B, Perry G: Neuronal and microglial involvement in beta-amyloid protein deposition in Alzheimer's disease. Am J Pathol 1990, 137:241-246.

13. Frautschy SA, Yang F, Irrizarry M, Hyman B, Saido TC, Hsiao K, Cole GM: Microglial response to amyloid plaques in APPsw transgenic mice. Am $J$ Pathol 1998, 152:307-317.
14. Wegiel J, Imaki H, Wang KC, Wronska A, Osuchowski M, Rubenstein R: Origin and turnover of microglial cells in fibrillar plaques of APPsw transgenic mice. Acta Neuropathol 2003, 105:393-402

15. Wegiel J, Wang KC, Imaki H, Rubenstein R, Wronska A, Osuchowski M, Lipinski WJ, Walker LC, LeVine H: The role of microglial cells and astrocytes in fibrillar plaque evolution in transgenic APP(SW) mice. Neurobiol Aging 2001, 22:49-61.

16. Stalder M, Phinney A, Probst A, Sommer B, Staufenbiel M, Jucker M: Association of microglia with amyloid plaques in brains of APP23 transgenic mice. Am J Pathol 1999, 154:1673-1684.

17. Styren SD, Civin WH, Rogers J: Molecular, cellular, and pathologic characterization of HLA-DR immunoreactivity in normal elderly and Alzheimer's disease brain. Exp Neurol 1990, 110:93-104.

18. Sasaki A, Shoji M, Harigaya Y, Kawarabayashi T, Ikeda M, Naito M, Matsubara E, Abe K, Nakazato Y: Amyloid cored plaques in Tg2576 transgenic mice are characterized by giant plaques, slightly activated microglia, and the lack of paired helical filament-typed, dystrophic neurites. Virchows Arch 2002, 441:358-367.

19. Griffin WS, Sheng JG, Roberts GW, Mrak RE: Interleukin-1 expression in different plaque types in Alzheimer's disease: significance in plaque evolution. J Neuropathol Exp Neurol 1995, 54:276-281.

20. Griffin WS, Nicoll JA, Grimaldi LM, Sheng JG, Mrak RE: The pervasiveness of interleukin-1 in Alzheimer pathogenesis: a role for specific polymorphisms in disease risk. Exp Gerontol 2000, 35:481-487.

21. Sheng JG, Mrak RE, Griffin WS: Glial-neuronal interactions in Alzheimer disease: progressive association of IL-1alpha + microglia and S100beta + astrocytes with neurofibrillary tangle stages. J Neuropathol Exp Neurol 1997, 56:285-290.

22. Johnstone $\mathrm{M}$, Gearing AJ, Miller KM: A central role for astrocytes in the inflammatory response to beta-amyloid; chemokines, cytokines and reactive oxygen species are produced. J Neuroimmunol 1999, 93:182-193.

23. Lee YB, Nagai A, Kim SU: Cytokines, chemokines, and cytokine receptors in human microglia. J Neurosci Res 2002, 69:94-103.

24. Combs CK, Bates P, Karlo JC, Landreth GE: Regulation of beta-amyloid stimulated proinflammatory responses by peroxisome proliferatoractivated receptor alpha. Neurochem Int 2001, 39:449-457.

25. Combs CK, Johnson DE, Karlo JC, Cannady SB, Landreth GE: Inflammatory mechanisms in Alzheimer's disease: inhibition of beta-amyloidstimulated proinflammatory responses and neurotoxicity by PPARgamma agonists. J Neurosci 2000, 20:558-567.

26. Banati RB, Gehrmann J, Schubert P, Kreutzberg GW: Cytotoxicity of microglia. Glia 1993, 7:111-118

27. Cleary JP, Walsh DM, Hofmeister JJ, Shankar GM, Kuskowski MA, Selkoe DJ, Ashe KH: Natural oligomers of the amyloid-beta protein specifically disrupt cognitive function. Nat Neurosci 2005, 8:79-84.

28. Combs CK, Karlo JC, Kao SC, Landreth GE: beta-Amyloid stimulation of microglia and monocytes results in TNFalpha-dependent expression of inducible nitric oxide synthase and neuronal apoptosis. J Neurosci 2001, 21:1179-1188

29. Del Bo R, Angeretti N, Lucca E, De Simoni MG, Forloni G: Reciprocal control of inflammatory cytokines, IL-1 and IL-6, and beta-amyloid production in cultures. Neurosci Lett 1995, 188:70-74.

30. Giulian D, Haverkamp LJ, Li J, Karshin WL, Yu J, Tom D, Li X, Kirkpatrick JB: Senile plaques stimulate microglia to release a neurotoxin found in Alzheimer brain. Neurochem Int 1995, 27:119-137.

31. Lesne S, Koh MT, Kotilinek L, Kayed R, Glabe CG, Yang A, Gallagher M, Ashe $\mathrm{KH}$ : A specific amyloid-beta protein assembly in the brain impairs memory. Nature 2006, 440:352-357.

32. Lue LF, Kuo YM, Roher AE, Brachova L, Shen Y Sue L, Beach T, Kurth JH, Rydel RE, Rogers J: Soluble amyloid beta peptide concentration as a predictor of synaptic change in Alzheimer's disease. Am J Pathol 1999, 155:853-862.

33. Klegeris A, Walker DG, McGeer PL: Interaction of Alzheimer beta-amyloid peptide with the human monocytic cell line THP-1 results in a protein kinase C-dependent secretion of tumor necrosis factor-alpha. Brain Res 1997, 747:114-121.

34. Klyubin I, Walsh DM, Lemere CA, Cullen WK, Shankar GM, Betts V, Spooner ET, Jiang L, Anwyl R, Selkoe DJ, Rowan MJ: Amyloid beta protein immunotherapy neutralizes Abeta oligomers that disrupt synaptic plasticity in vivo. Nat Med 2005, 11:556-561 
35. McLean CA, Cherny RA, Fraser FW, Fuller SJ, Smith MJ, Beyreuther K, Bush Al, Masters $\mathrm{CL}$ : Soluble pool of Abeta amyloid as a determinant of severity of neurodegeneration in Alzheimer's disease. Ann Neurol 1999, 46:860-866.

36. Roher AE, Chaney MO, Kuo YM, Webster SD, Stine WB, Haverkamp L, Woods AS, Cotter RJ, Tuohy JM, Krafft GA, Bonnell BS, Emmerling MR: Morphology and toxicity of Abeta-(1-42) dimer derived from neuritic and vascular amyloid deposits of Alzheimer's disease. J Biol Chem 1996, 271:20631-20635.

37. Breitner JC, Baker LD, Montine TJ, Meinert CL, Lyketsos CG, Ashe KH, Brandt J, Craft S, Evans DE, Green RC, Ismail MS, Martin BK, Mullan MJ, Sabbagh M, Tariot PN: ADAPT Research Group: Extended results of the Alzheimer's disease anti-inflammatory prevention trial. Alzheimers Dement 2011, 7:402-411.

38. Sondag CM, Dhawan G, Combs CK: Beta amyloid oligomers and fibrils stimulate differential activation of primary microglia. J Neuroinflammation 2009, 6:1.

39. McDonald DR, Brunden KR, Landreth GE: Amyloid fibrils activate tyrosine kinase-dependent signaling and superoxide production in microglia. $J$ Neurosci 1997, 17:2284-2294.

40. Moore KJ, El Khoury J, Medeiros LA, Terada K, Geula C, Luster AD, Freeman MW: A CD36-initiated signaling cascade mediates inflammatory effects of beta-amyloid. J Biol Chem 2002, 277:47373-47379.

41. Combs CK, Johnson DE, Cannady SB, Lehman TM, Landreth GE: Identification of microglial signal transduction pathways mediating a neurotoxic response to amyloidogenic fragments of beta-amyloid and prion proteins. J Neurosci 1999, 19:928-939.

42. Wood JG, Zinsmeister P: Tyrosine phosphorylation systems in Alzheimer's disease pathology. Neurosci Lett 1991, 121:12-16.

43. Koenigsknecht J, Landreth G: Microglial phagocytosis of fibrillar betaamyloid through a beta1 integrin-dependent mechanism. J Neurosci 2004, 24:9838-9846

44. Bamberger ME, Harris ME, McDonald DR, Husemann J, Landreth GE: A cell surface receptor complex for fibrillar beta-amyloid mediates microglial activation. J Neurosci 2003, 23:2665-2674.

45. Wilkinson B, Koenigsknecht-Talboo J, Grommes C, Lee CY, Landreth G: Fibrillar beta-amyloid-stimulated intracellular signaling cascades require Vav for induction of respiratory burst and phagocytosis in monocytes and microglia. J Biol Chem 2006, 281:20842-20850.

46. Nakai M, Hojo K, Taniguchi T, Terashima A, Kawamata T, Hashimoto T, Maeda K, Tanaka C: PKC and tyrosine kinase involvement in amyloid beta (25-35)-induced chemotaxis of microglia. Neuroreport 1998, 9:3467-3470.

47. McDonald DR, Bamberger ME, Combs CK, Landreth GE: beta-Amyloid fibrils activate parallel mitogen-activated protein kinase pathways in microglia and THP1 monocytes. J Neurosci 1998, 18:4451-4460.

48. Tan J, Town T, Mori T, Wu Y, Saxe M, Crawford F, Mullan M: CD45 opposes beta-amyloid peptide-induced microglial activation via inhibition of p44/42 mitogen-activated protein kinase. J Neurosci 2000, 20:7587-7594

49. Tan J, Town T, Mullan M: CD45 inhibits CD40L-induced microglial activation via negative regulation of the Src/p44/42 MAPK pathway. $J$ Biol Chem 2000, 275:37224-37231.

50. Dhawan G, Floden AM, Combs CK: Amyloid-beta oligomers stimulate microglia through a tyrosine kinase dependent mechanism. Neurobiol Aging 2011, Epub ahead of print.

51. Jankowsky JL, Fadale DJ, Anderson J, Xu GM, Gonzales V, Jenkins NA Copeland NG, Lee MK, Younkin LH, Wagner SL, Younkin SG, Borchelt DR: Mutant presenilins specifically elevate the levels of the 42 residue beta-amyloid peptide in vivo: evidence for augmentation of a 42-specific gamma secretase. Hum Mol Genet 2004, 13:159-170.

52. Jankowsky JL, Slunt HH, Ratovitski T, Jenkins NA, Copeland NG, Borchelt DR Co-expression of multiple transgenes in mouse CNS: a comparison of strategies. Biomol Eng 2001, 17:157-165.

53. Floden AM, Li S, Combs CK: Beta-amyloid-stimulated microglia induce neuron death via synergistic stimulation of tumor necrosis factor alpha and NMDA receptors. J Neurosci 2005, 25:2566-2575.

54. Fezoui Y, Hartley DM, Harper JD, Khurana R, Walsh DM, Condron MM, Selkoe DJ, Lansbury PT Jr, Fink AL, Teplow DB: An improved method of preparing the amyloid beta-protein for fibrillogenesis and neurotoxicity experiments. Amyloid 2000, 7:166-178.
55. Bradford MM: A rapid and sensitive method for the quantitation of microgram quantities of protein utilizing the principle of protein-dye binding. Anal Biochem 1976, 72:248-254.

56. Wenk GL: Assessment of spatial memory using the T maze. Current protocols in neuroscience 1998, Supplement 4(8):5B. 1-8.5B.7.

57. Lombardo LJ, Lee FY, Chen P, Norris D, Barrish JC, Behnia K, Castaneda S, Cornelius LA, Das J, Doweyko AM, Fairchild C, Hunt JT, Inigo I, Johnston K, Kamath A, Kan D, Klei H, Marathe P, Pang S, Peterson R, Pitt S, Schieven GL, Schmidt RJ, Tokarski J, Wen ML, Wityak J, Borzilleri RM: Discovery of N(2-chloro-6-methyl- phenyl)-2-(6-(4-(2-hydroxyethyl)- piperazin-1-yl)-2methylpyrimidin-4- ylamino)thiazole-5-carboxamide (BMS-354825), a dual Src/Abl kinase inhibitor with potent antitumor activity in preclinical assays. J Med Chem 2004, 47:6658-6661

58. Nam S, Kim D, Cheng JQ, Zhang S, Lee JH, Buettner R, Mirosevich J, Lee FY, Jove R: Action of the Src family kinase inhibitor, dasatinib (BMS-354825), on human prostate cancer cells. Cancer Res 2005, 65:9185-9189.

59. Porkka K, Koskenvesa P, Lundan T, Rimpilainen J, Mustjoki S, Smykla R, Wild R, Luo R, Arnan M, Brethon B, Eccersley L, Hjorth-Hansen H, Höglund M, Klamova H, Knutsen H, Parikh S, Raffoux E, Gruber F, Brito-Babapulle F, Dombret H, Duarte RF, Elonen E, Paquette R, Zwaan CM, Lee FY: Dasatinib crosses the blood-brain barrier and is an efficient therapy for central nervous system Philadelphia chromosome-positive leukemia. Blood 2008, 112:1005-1012.

60. Schlatterer SD, Tremblay MA, Acker CM, Davies P: Neuronal c-Abl overexpression leads to neuronal loss and neuroinflammation in the mouse forebrain. J Alzheimers Dis 2011, 25:119-133.

61. Greenberg S, Chang P, Wang DC, Xavier R, Seed B: Clustered syk tyrosine kinase domains trigger phagocytosis. Proc Natl Acad Sci U S A 1996, 93:1103-1107.

62. Aderem A, Underhill DM: Mechanisms of phagocytosis in macrophages. Annu Rev Immunol 1999, 17:593-623.

63. Fitzer-Attas CJ, Lowry M, Crowley MT, Finn AJ, Meng F, DeFranco AL, Lowell CA: Fcgamma receptor-mediated phagocytosis in macrophages lacking the Src family tyrosine kinases Hck, Fgr, and Lyn. J Exp Med 2000, 191:669-682.

64. Stewart S, Cacucci F, Lever C: Which memory task for my mouse? A systematic review of spatial memory performance in the tg2576 Alzheimer's mouse model. J Alzheimers Dis 2011, 26:105-126.

65. Duncan PM, Duncan NC: Free-operant and T-maze avoidance performance by septal and hippocampal-damaged rats. Physiol Behav 1971, 7:687-693

66. Loesche J, Steward O: Behavioral correlates of denervation and reinnervation of the hippocampal formation of the rat: recovery of alternation performance following unilateral entorhinal cortex lesions. Brain Res Bull 1977, 2:31-39.

67. Floden AM, Combs CK: Beta-amyloid stimulates murine postnatal and adult microglia cultures in a unique manner. J Neurosci 2006, 26:4644-4648

68. Akiyama H, Barger S, Barnum S, Bradt B, Bauer J, Cole GM, Cooper NR, Eikelenboom P, Emmerling M, Fiebich BL, Finch CE, Frautschy S, Griffin WS, Hampel H, Hull M, Landreth G, Lue L, Mrak R, Mackenzie IR, McGeer PL, O'Banion MK, Pachter J, Pasinetti G, Plata-Salaman C, Rogers J, Rydel R, Shen Y, Streit W, Strohmeyer R, Tooyoma I, et al: Inflammation and Alzheimer's disease. Neurobiol Aging 2000, 21:383-421.

69. Jara JH, Singh BB, Floden AM, Combs CK: Tumor necrosis factor alpha stimulates NMDA receptor activity in mouse cortical neurons resulting in ERK-dependent death. J Neurochem 2007, 100:1407-1420.

70. Aisen PS, Schafer KA, Grundman M, Pfeiffer E, Sano M, Davis KL, Farlow MR, Jin S, Thomas RG, Thal LJ: Effects of rofecoxib or naproxen vs placebo on Alzheimer disease progression: a randomized controlled trial. Jama 2003 289:2819-2826.

71. Thal LJ, Ferris SH, Kirby L, Block GA, Lines CR, Yuen E, Assaid C, Nessly ML, Norman BA, Baranak CC, Reines SA: Rofecoxib Protocol 078 study group: A randomized, double-blind, study of rofecoxib in patients with mild cognitive impairment. Neuropsychopharmacology 2005, 30:1204-1215.

72. Aisen PS, Schmeidler J, Pasinetti GM: Randomized pilot study of nimesulide treatment in Alzheimer's disease. Neurology 2002, 58:1050-1054

73. Rogers J, Kirby LC, Hempelman SR, Berry DL, McGeer PL, Kaszniak AW, Zalinski J, Cofield M, Mansukhani L, Willson P, et al: Clinical trial of indomethacin in Alzheimer's disease. Neurology 1993, 43:1609-1611. 
74. Scharf S, Mander A, Ugoni A, Vajda F, Christophidis N: A double-blind, placebo-controlled trial of diclofenac/misoprostol in Alzheimer's disease. Neurology 1999, 53:197-201.

75. Karp HL, Tillotson ML, Soria J, Reich C, Wood JG: Microglial tyrosine phosphorylation systems in normal and degenerating brain. Glia 1994, 11:284-290.

76. Tillotson ML, Wood JG: Phosphotyrosine antibodies specifically label ameboid microglia in vitro and ramified microglia in vivo. Glia 1989, 2:412-419.

77. Tillotson ML, Wood JG: Tyrosine phosphorylation in the postnatal rat brain: a developmental, immunohistochemical study. J Comp Neurol 1989, 282:133-141.

78. Combs CK: Inflammation and microglia actions in Alzheimer's disease. J Neuroimmune Pharmacol 2009, 4:380-388.

79. Tobinick EL, Gross H: Rapid cognitive improvement in Alzheimer's disease following perispinal etanercept administration. J Neuroinflammation 2008, $5: 2$.

80. Wong G, Muller O, Clark R, Conroy L, Moran MF, Polakis P, McCormick F: Molecular cloning and nucleic acid binding properties of the GAPassociated tyrosine phosphoprotein p62. Cell 1992, 69:551-558.

81. Broome MA, Hunter T: The PDGF receptor phosphorylates Tyr 138 in the c-Src SH3 domain in vivo reducing peptide ligand binding. Oncogene 1997, 14:17-34.

82. Barone MV, Courtneidge SA: Myc but not Fos rescue of PDGF signalling block caused by kinase-inactive Src. Nature 1995, 378:509-512.

83. Klinghoffer RA, Sachsenmaier C, Cooper JA, Soriano P: Src family kinases are required for integrin but not PDGFR signal transduction. EMBO 1999, 18:2459-24571.

84. Taylor SJ, Shalloway D: Src and the control of cell division. Bioessays 1996, 18:9-11.

85. Yoshimura M, Iwasaki Y, Kaji A: In vitro differentiation of chicken embryo skin cells transformed by Rous sarcoma virus. J Cell Physiol 1981 109:373-385.

86. Alema S, Tato F: Interaction of retroviral oncogenes with the differentiation program of myogenic cells. Adv Cancer Res 1987, 49:1-28.

87. Haltmeier $\mathrm{H}$, Rohrer $\mathrm{H}$ : Distinct and different effects of the oncogenes vmyc and v-src on avian sympathetic neurons: retroviral transfer of v-myc stimulates neuronal proliferation whereas v-src transfer enhances neuronal differentiation. J Cell Biol 1990, 110:2087-2098.

88. Hecker G, Lewis DL, Rausch DM, Jelsema CL: Nerve-growth-factor-treated and v-src-expressing PC 12 cells: a model for neuronal differentiation. Biochem Soc Trans 1991, 19:385-386.

89. Tatosyan AG, Mizenina OA: Kinases of the Src family: structure and functions. Biochemistry (Mosc) 2000, 65:49-58.

90. Grant SG, O'Dell TJ, Karl KA, Stein PL, Soriano P, Kandel ER: Impaired longterm potentiation, spatial learning, and hippocampal development in fyn mutant mice. Science 1992, 258:1903-1910.

91. Grant SG, Silva AJ: Targeting learning. Trends Neurosci 1994, 17:71-75.

92. Kojima N, Wang J, Mansuy IM, Grant SG, Mayford M, Kandel ER: Rescuing impairment of long-term potentiation in fyn-deficient mice by introducing Fyn transgene. Proc Natl Acad Sci U S A 1997, 94:4761-4765.

93. Maness PF: Nonreceptor protein tyrosine kinases associated with neuronal development. Dev Neurosci 1992, 14:257-270.

94. Sinai L, Duffy $S$, Roder JC: Src inhibition reduces NR2B surface expression and synaptic plasticity in the amygdala. Learn Mem 2010, 17:364-371.

95. Tremblay MA, Acker CM, Davies P: Tau phosphorylated at tyrosine 394 is found in Alzheimer's disease tangles and can be a product of the Ablrelated kinase, Arg. J Alzheimers Dis 2011, 19:721-733.

96. Jing Z, Caltagarone J, Bowser R: Altered subcellular distribution of c-Abl in Alzheimer's disease. J Alzheimers Dis 2009, 17:409-422.

97. Vazquez MC, Vargas LM, Inestrosa NC, Alvarez AR: c-Abl modulates AICD dependent cellular responses: transcriptional induction and apoptosis. $J$ Cell Physiol 2009, 220:136-143.

98. Tremblay MA, Acker CM, Davies P: Tau phosphorylated at tyrosine 394 is found in Alzheimer's disease tangles and can be a product of the Ablrelated kinase, Arg. J Alzheimers Dis 2010, 19:721-733.

99. Imam SZ, Zhou Q, Yamamoto A, Valente AJ, Ali SF, Bains M, Roberts JL, Kahle PJ, Clark RA, Li S: Novel regulation of parkin function through c-Ablmediated tyrosine phosphorylation: implications for Parkinson's disease. J Neurosci 2011, 31:157-163.
100. Ko HS, Lee Y, Shin JH, Karuppagounder SS, Gadad BS, Koleske AJ, Pletnikova O, Troncoso JC, Dawson VL, Dawson TM: Phosphorylation by the c-Abl protein tyrosine kinase inhibits parkin's ubiquitination and protective function. Proc Natl Acad Sci U S A 2010, 107:16691-16696.

101. Lebouvier T, Scales TM, Williamson R, Noble W, Duyckaerts C, Hanger DP, Reynolds $\mathrm{CH}$, Anderton $\mathrm{BH}$, Derkinderen P: The microtubule-associated protein tau is also phosphorylated on tyrosine. J Alzheimers Dis 2009, 18:1-9.

102. Cancino Gl, Perez De Arce K, Castro PU, Toledo EM, Von Bernhardi R, Alvarez AR: c-Abl tyrosine kinase modulates tau pathology and Cdk5 phosphorylation in AD transgenic mice. Neurobiol Aging 2011, 32:1249-1261

103. Shah NP, Tran C, Lee FY, Chen P, Norris D, Sawyers CL: Overriding imatinib resistance with a novel $A B L$ kinase inhibitor. Science 2004, 305:399-401.

104. Sawyers CL: Chronic myeloid leukemia. N Engl J Med 1999, 340:1330-1340.

doi:10.1186/1742-2094-9-117

Cite this article as: Dhawan and Combs: Inhibition of Src kinase activity attenuates amyloid associated microgliosis in a murine model of Alzheimer's disease. Journal of Neuroinflammation 2012 9:117.

\section{Submit your next manuscript to BioMed Central and take full advantage of:}

- Convenient online submission

- Thorough peer review

- No space constraints or color figure charges

- Immediate publication on acceptance

- Inclusion in PubMed, CAS, Scopus and Google Scholar

- Research which is freely available for redistribution 